\title{
Re-descriptions of eight chigger mite species (Acariformes: Trombiculidae) of the Leptotrombidium generic complex from Vietnam
}

\author{
ALEXANDR A. STEKOLNIKOV ${ }^{1, *} \&$ ANASTASIA A. ANTONOVSKAIA ${ }^{2}$ \\ ${ }^{1}$ Zoological Institute of the Russian Academy of Sciences, Universitetskaya embankment 1, Saint Petersburg 199034, Russia \\ ${ }^{2}$ Lomonosov Moscow State University, Moscow, Russia. "an.antonovskaia@gmail.com; @ https://orcid.org/0000-0001-8638-7151 \\ *Corresponding author. झ"Alexandr.Stekolnikov@zin.ru; @ https://orcid.org/0000-0001-7548-2671
}

\begin{abstract}
Six mite species of the genus Leptotrombidium Nagayo, Miyagawa, Mitamura and Imamura, 1916 and one species from each of the genera Lorillatum Nadchatram, 1963 and Trombiculindus Radford, 1948, incompletely described by Schluger et al. (1960b, 1963) from rodents and tree shrews in North Vietnam, are re-described based on type series. Lectotypes and paralectotypes have been designated for all redescribed species. Two new synonyms have been established: Leptotrombidium magnum (Schluger, 1960) (= Leptotrombidium dooleyi Nadchatram, 1970, syn. nov.; = Leptotrombidium submagnum Wang, Li and Shi, 1988, syn. nov.).
\end{abstract}

Key words: chiggers, taxonomy, Vietnam, Southeast Asia

\section{Introduction}

The genus Leptotrombidium Nagayo, Miyagawa, Mitamura and Imamura, 1916 is the most speciose genus of chigger mites currently including more than 340 species (Stekolnikov 2013). All proved vectors of scrub typhus in the Indomalayan realm belong to Leptotrombidium (Santibáñez et al. 2015) that causes a necessity of the exact identification of its species. At the same time, a reliable classification and identification of Leptotrombidium species is difficult due to a deficiency of distinctive morphological characters in this genus combined with a significant intraspecific variability (Stekolnikov 2013). Moreover, many species were described insufficiently and require reexamination. Thus, descriptions of species from Vietnam, which were published by Schluger et al. (1960b), missed such important taxonomic characters, as details of leg setation, exact number of idiosomal setae, and measurements of scutum, except for its width and length. The shape of idiosomal setae with their barbs and the puncta of scutum that significantly contribute to the visual recognition of mite species were figured too schematically.

Vercammen-Grandjean \& Langston (1976) redescribed a part of these species based on syntypes. They examined one syntype of Leptotrombidium globosum (Schluger, 1960), four syntypes of L. gracipalpe (Schluger, 1960), ten syntypes of $L$. horridum (Schluger, 1960), five syntypes of L. magnum (Schluger, 1960), and three syntypes of $L$. monstrosum (Schluger, 1960). Although the figures of scutum and setae provided by Vercammen-Grandjean for the listed species are highly detailed and excellently reflect the characteristics of redescribed species, these drawings are significantly idealized. We believe that microphotographs and drawings prepared with the use of a drawing tube would be more useful for identification of species. In addition, the cited work does not include images of idiosoma showing the arrangement of its setae. Meanwhile, the pattern of idiosomal setation is also an important character, because it does not boil down only to the disposition of setae by rows. Configuration of the rows can be diverse and the assignment of setae to particular rows can be ambiguous, especially in the case of increase of setal number that is common in chigger mites.

One more problem concerning the type materials mounted by Schluger is that they are represented by microscope slides each containing a series of specimens (4-5 or more) sometimes belonging to different species of the same genus (Antonovskaia \& Stekolnikov 2021). For example, the slide ZMMU Tdt-3266, according to the original label, contains specimens of three Leptotrombidium species - L. magnum, L. gracipalpe, and L. horridum; the slide 
ZMMU Tdt-3268 included L. magnum, L. monstrosum, and L. horridum. The slide ZMMU Tdt-3276 labeled as "Trombicula globosa" turned out to include only one specimen of L. globosum, but four specimens of L. magnum. Taking into account that individual specimens were not marked on the slides and that holotypes were not designated in the original descriptions, the separation of type series from other specimens is a nontrivial task. Each researcher who first faces with this collection can see there a set of different species mounted on slides and a set of species names on labels, but the collection itself does not provide him with any means to establish a definite connection between the specimens and the names. Therefore, a designation of individual type specimens in this collection is important to provide a base of its posterior use for taxonomic purposes.

In the present paper, addition to six species of Leptotrombidium described by Schluger et al. (1960b), we redescribe one species of the genus Lorillatum Nadchatram, 1963, which was included by Vercammen-Grandjean \& Langston (1976) in the Leptotrombidium generic complex, and one species of the genus Trombiculindus Radford, 1948 considered by these authors as a subgenus of Leptotrombidium. Both species from the genera Lorillatum and Trombiculindus were also described by Schluger et al. (1963) from Vietnam.

\section{Materials and methods}

The present work was based on the materials (107 microscope slides) deposited in the Zoological Museum of Moscow State University (ZMMU, Moscow, Russia). The methods of their examination were described elsewhere (Antonovskaia \& Stekolnikov 2021). Microphotographs and drawings were made with the use of a microscope Leica DM2500 (Leica Microsystems GmbH, Wetzlar, Germany) supplied with a digital camera Leica DMC 4500 and a drawing tube, using differential interference contrast (DIC). Measurements were taken from photos by the calibrated software ToupView (Hangzhou ToupTek Photonics Co., Zhejiang, China) and ImageJ (Fiji) (Schindelin et al. 2012); the photos were captured on a Micromed-3 Professional Microscope (Ningbo Sheng Heng Optics \& Electronics Co., Ltd., Ningbo, China) equipped with phase contrast and a digital camera ToupCam TP705100A (Hangzhou ToupTek Photonics Co., Zhejiang, China).

Unlike our previous practice, we signed numbers of individual specimens directly on slides. We did not perform a re-mounting of slides, because it could cause a damage of specimens.

Schluger originally labeled the slides by Indian ink directly on a glass. After their donation to ZMMU, Kudryashova provided the slides with paper labels and accession numbers (Antonovskaia \& Stekolnikov 2021). However, syntypes of $L$. horridum were not numbered and we gave them our own numbers (from 1 to 9 ). We took the revised host names from the unpublished thesis of Grochovskaja (Antonovskaia \& Stekolnikov 2021). The host names inscribed on a glass or included in the paper labels are given in brackets if they are different from revised versions.

Contrary to other works of the same research team (Schluger et al. 1959, 1960a, c, 1961, 1963), the authorship consisting of only one name (Schluger) was definitely included in the descriptions of six species of Leptotrombidium s. str. (Schluger et al. 1960b). Therefore, names of these species must be cited in the form: Leptotrombidium arvinum (Schluger, 1960) (in Schluger et al. 1960b).

We continue to use the specific morphological terminology accepted in the taxonomy of chigger mites since the 1950s (Goff et al. 1982). Standard abbreviations of the specialized leg setae (e.g. PT', ST, S ) are given in figures; in descriptions, only the full names (pretarsala, subterminala, tarsala) and designations by Greek letters $(\zeta, \omega)$ are included.

\section{Results}

Family Trombiculidae Ewing, 1944

Subfamily Trombiculinae Ewing, 1929

Tribe Trombiculini Vercammen-Grandjean, 1960

Genus Leptotrombidium Nagayo, Miyagawa, Mitamura and Imamura, 1916 


\section{Leptotrombidium arvinum (Schluger, 1960)}

(Figs. 1, 2)

Trombicula (Leptotrombidium) arvina Schluger, 1960 (in Schluger et al. 1960b): 1792, fig. 2.

Leptotrombidium (Leptotrombidium) arvina: Traub \& Lakshana 1966: 271, figs. 1-5; Lakshana 1973: 6; Chau et al. 2007: 40, fig. 15.

Leptotrombidium (Leptotrombidium) miculum arvinum: Vercammen-Grandjean \& Langston 1976: 422, pl. 100; Xiang \& Wen 1984: 260; Wen 1984: 308.

Leptotrombidium (Leptotrombidium) arvinum: Kudryashova 2004: 13.

Leptotrombidium arvinum: Chaisiri et al. 2016: 323; Stekolnikov 2013: 69; 2021: 112.

Diagnosis. $\mathrm{SIF}=7 \mathrm{~B}-\mathrm{B}-3-2111.0000 ; \mathrm{fsp}=7.7 .7 ; \mathrm{fCx}=1.1 .1 ; \mathrm{fSt}=2.2 ; \mathrm{fPp}=\mathrm{N} / \mathrm{N} / \mathrm{BNN} ; \mathrm{fSc}: \mathrm{PL}>\mathrm{AM}>\mathrm{AL} ; \mathrm{Ip}=$ 601-625; fD = 2H-8-6-6-2-2; DS = 26-28; V = 23-24; NDV = 49-52. Standard measurements of type series given in Table 1.

TABLE 1. Morphometric (AW-Ip, $\mu \mathrm{m})$ and meristic (DS-NDV) traits of Leptotrombidium arvinum (Schluger, 1960) (n $=3)$.

\begin{tabular}{|c|c|c|c|}
\hline & Range & Mean & Lectotype \\
\hline AW & $55-57$ & 56 & 55 \\
\hline PW & $61-64$ & 62 & 61 \\
\hline SB & $25-29$ & 27 & 25 \\
\hline ASB & $23-24$ & 23 & 24 \\
\hline PSB & $13-17$ & 14 & 17 \\
\hline SD & $35-41$ & 38 & 41 \\
\hline P-PL & $19-24$ & 21 & 24 \\
\hline AP & $14-16$ & 15 & 16 \\
\hline $\mathrm{AM}$ & $44-50$ & 47 & 46 \\
\hline $\mathrm{AL}$ & $35-39$ & 37 & 37 \\
\hline PL & $59-64$ & 61 & 59 \\
\hline $\mathrm{H}$ & $60-61$ & 60 & 60 \\
\hline $\mathrm{D}_{\text {min }}$ & $34-40$ & 37 & 34 \\
\hline $\mathrm{D}_{\max }$ & $52-55$ & 54 & 55 \\
\hline $\mathrm{V}_{\min }$ & $17-20$ & 19 & 19 \\
\hline $\mathrm{V}_{\text {max }}$ & $33-45$ & 40 & 33 \\
\hline pa & $207-214$ & 211 & 207 \\
\hline $\mathrm{pm}$ & $183-190$ & 187 & 190 \\
\hline $\mathrm{pp}$ & $204-225$ & 218 & 225 \\
\hline Ip & $601-625$ & 616 & 622 \\
\hline DS & $26-28$ & 27 & 28 \\
\hline V & $23-24$ & 24 & 24 \\
\hline NDV & $49-52$ & 51 & 52 \\
\hline
\end{tabular}

Description (larva) (based on lectotype and 2 paralectotypes, fD recorded in one specimen). IDIOSOMA (Figs. 1A, 2B-G). Eyes $2+2 ; 26-28$ barbed dorsal idiosomal setae, including one pair of humeral setae, arranged 2H-8-6-6-2-2; 4 sternal setae; $23-24$ ventral setae; NDV $=49-52$.

GNATHOSOMA (Fig. 2H, I). Cheliceral blade with tricuspid cap; gnathobase with sparse puncta and 1 pair of branched gnathocoxal (tritorostral) setae; proximal part of cheliceral base and palpal femur with sparse puncta; galeal (deutorostral) seta branched; palpal claw with 3 prongs; setae on palpal femur and genu nude; dorsal palpal tibial seta branched, lateral and ventral palpal tibial setae nude; palpal tarsus with 7 branched setae and tarsala $(\omega)$.

SCUTUM (Figs. 1, 2A). Rectangular, moderately covered with rather large puncta, greatly projected posterior to PL, posterior margin almost straight in middle part; AM posterior to level of AL, sensillary (trichobothrial) bases 
posterior to level of PL (P-PL - PSB $=6-8 \mu \mathrm{m}$ ); AL and PL densely covered with rather long thin barbs, PL slightly expanded proximally, covered with shorter and wider barbs, similarly to dorsal idiosomal setae; PL > AM > AL; flagelliform sensilla (trichobothria), with about 11 long branches in distal half.

LEGS (Fig. 2J-L). All 7-segmented, with 1 pair of claws and claw-like empodium. Leg I: coxa with 1 branched seta (1B); trochanter 1B; basifemur 1B; telofemur 5B; genu 4B, 2 genualae $(\sigma)$, microgenuala $(\kappa)$; tibia $8 \mathrm{~B}, 2$ tibialae $(\varphi)$, microtibiala $(\kappa)$; tarsus $21 \mathrm{~B}$, tarsala $(\omega)$, microtarsala $(\varepsilon)$ distal to tarsala, subterminala $(\zeta)$, parasubterminala $(z)$, pretarsala $(\zeta)$. Leg II: coxa 1B; trochanter 1B; basifemur 2B; telofemur 4B; genu 3B, genuala; tibia 6B, 2 tibialae $(\varphi)$; tarsus $16 \mathrm{~B}$, tarsala $(\omega)$, microtarsala $(\varepsilon)$ posterior to tarsala, pretarsala $(\zeta)$. Leg III: coxa 1B; trochanter 1B; basifemur 2B; telofemur 3B; genu 3B, genuala; tibia 6B, tibiala; tarsus $15 \mathrm{~B}$.

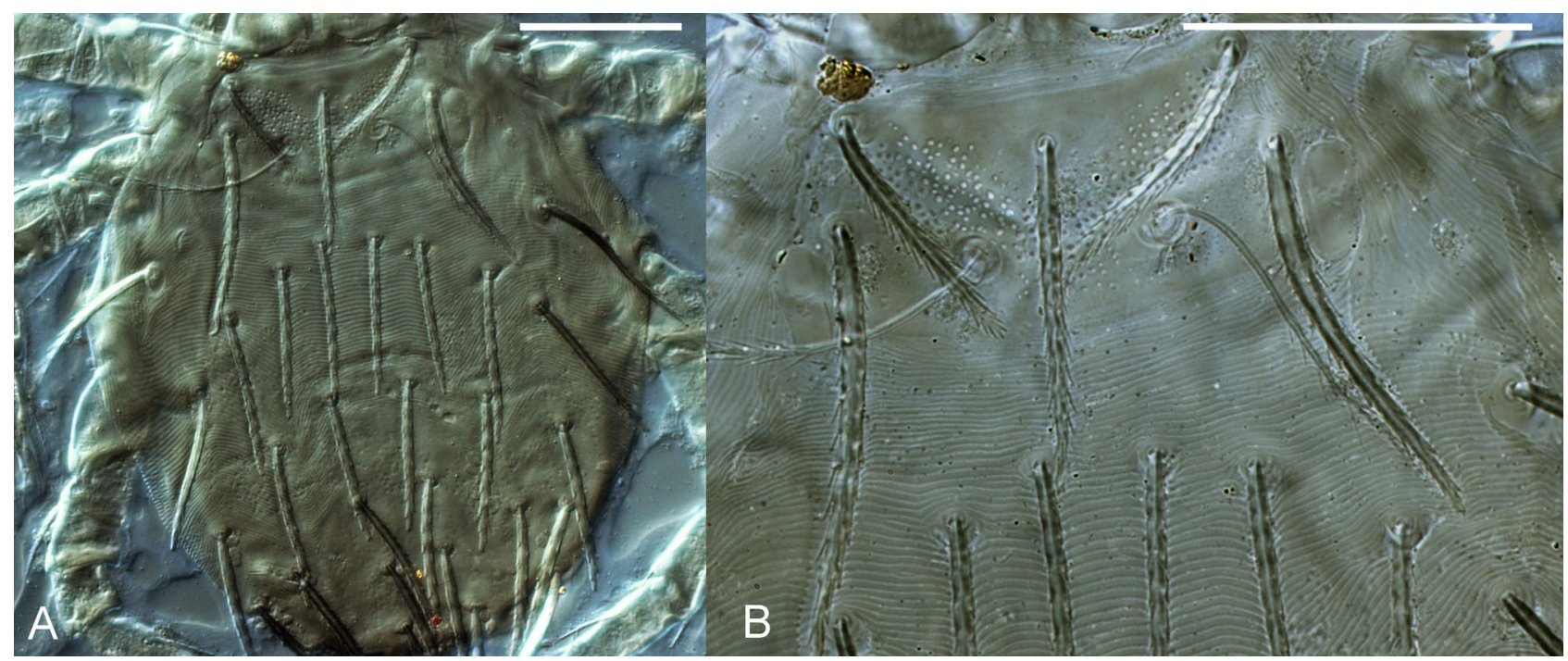

FIGURE 1. Leptotrombidium arvinum (Schluger, 1960), paralectotype ZMMU Tdt-3144, specimen 2. A, dorsal aspect of idiosoma; B, scutum. Scale bars: $50 \mu \mathrm{m}$.

Distribution and hosts. This species was described from North Vietnam, Nghe An Province, ex Tupaia sp. (Schluger et al. 1960b). Later on, it was recorded in the following countries: in Thailand, from mammals Tupaia glis (Diard and Duvaucel), Callosciurus caniceps (Gray), C. erythraeus (Pallas), C. finlaysonii (Horsfield), Crocidura horsfieldii (Tomes), Hylomys suillus S. Müller, Maxomys rajah (Thomas) (= Rattus rajah), Menetes berdmorei (Blyth), Niviventer niviventer (Hodgson) (= Rattus niveiventer), Rattus rattus (L.), Berylmys berdmorei (Blyth) (= Rattus berdmorei), Paradoxurus hermaphroditus (Pallas), and birds Chalcophaps indica (L.), Pellorneum ruficeps Swainson (Traub \& Lakshana 1966), and Leopoldamys sabanus (= Rattus sabanus) (Lakshana 1973); in Laos, from T. glis and Dremomys rufigenis (Blanford); in Malaysia, from Tupaia sp. and Callosciurus caniceps (VercammenGrandjean \& Langston 1976), and in China, from the specimens collected with a black plate (Wen 1984).

Type material examined. Lectotype larva (ZMMU Tdt-3144, specimen 4, designated here) ex Tupaia sp. No 611, VIETNAM: Nghe An Province, Phu Quy, 15 September 1956, coll. I.M. Grochovskaja. One paralectotype larva (ZMMU Tdt-3144, specimen 2) with same data as lectotype; one paralectotype larva (ZMMU Tdt-3143, specimen 3) ex Tupaia sp. No 610, other data same as for lectotype.

Remarks. According to the cluster analysis performed by Stekolnikov (2013), L. arvinum belongs to the arvinum species group, which includes also L. saigoni Stekolnikov, 2013. The latter was described as Leptotrombidium (Leptotrombidium) miculum arvinum var. saigoni Vercammen-Grandjean and Langston, 1976, from a single specimen, and raised to species by Stekolnikov (2013). This species differs from $L$. arvinum by the presence of 10 setae in $1^{\text {st }}$ posthumeral row, vs. $8, \mathrm{NDV}=58 \mathrm{vs.} 49-52$, and by slightly longer legs (Ip $\left.=732 \mathrm{vs.} 601-625\right)$.

Vercammen-Grandjean \& Langston (1976) included L. arvinum in L. miculum, as a subspecies. However, according to Stekolnikov (2013), L. miculum belongs to the arenicola species group. The latter species differs from L. arvinum in having the sensillary bases situated at the level of PL vs. posterior to PL, shorter scutal setae (AM 32-38, AL 27-32, and PL 40-46, vs. 44-50, 35-39, 59-64, respectively), shorter idiosomal setae (H 41-43, $\mathrm{D}_{\min }$ $31-32, \mathrm{D}_{\max } 37-40$, and $\mathrm{V}_{\max } 31-33$ vs. 60-61, 34-40, 52-55, and 33-45, respectively), and slightly shorter legs (Ip 554-602 vs. 601-625). 

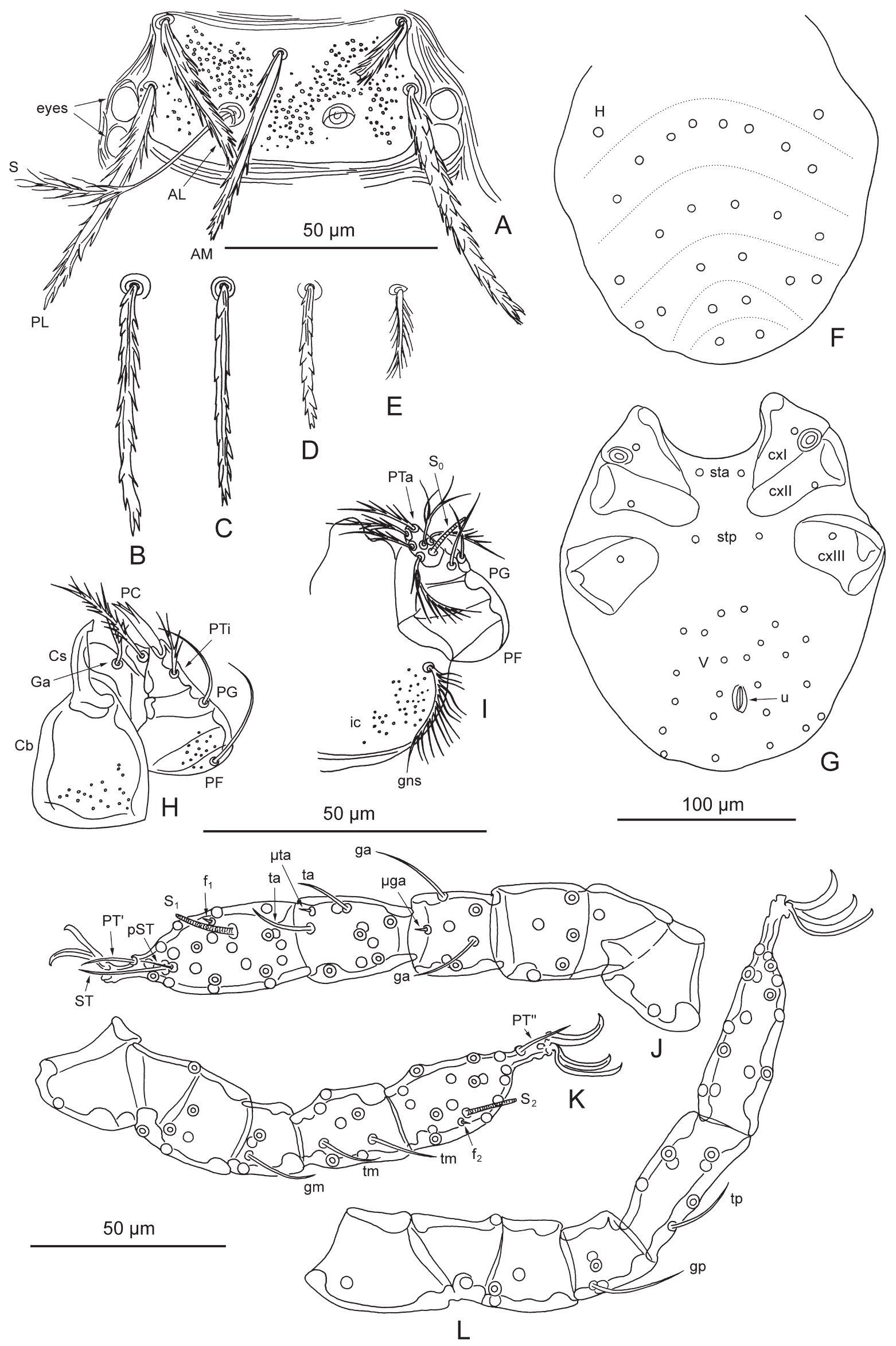
FIGURE 2. Leptotrombidium arvinum (Schluger, 1960). A, scutum of lectotype (right sensillum lost, right AL broken); B, humeral seta (C antero-marginal) of lectotype; C, dorsal idiosomal seta of $2^{\text {nd }}$ posthumeral row (D) of lectotype; D, postanal seta of lectotype; E, preanal seta of lectotype; F, arrangement of dorsal idiosomal setae in paralectotype ZMMU Tdt-3144, specimen 2; G, ventral aspect of idiosoma in paralectotype ZMMU Tdt-3144, specimen 2; H, dorsal aspect of gnathosoma of lectotype; I, ventral aspect of gnathosoma of lectotype; J, leg I (trochanter-tarsus) of lectotype (one claw lost); K, leg II (trochanter-tarsus) of lectotype; L, leg III (trochanter-tarsus) of lectotype. Abbreviations: AL, anterolateral scutal seta; AM, anteromedian scutal seta; $\mathrm{Cb}$, cheliceral base; Cs, cheliceral blade; cxI, leg coxa I; cxII, leg coxa II; cxIII, leg coxa III; $\mathrm{f}_{1}$, microtarsala I $(\varepsilon)$; $\mathrm{f}_{2}$, microtarsala II $(\varepsilon)$; Ga, galeal (deutorostral) seta; ga, genuala I $(\sigma)$; gm, genuala II $(\sigma)$; gns, gnathocoxal (tritorostral) seta; gp, genuala III $(\sigma)$; H, humeral seta; ic, infracapitulum (gnathobase); $\mu$ ga, microgenuala I $(\kappa)$; $\mu$ ta, microtibiala I $(\kappa)$; PC, palpal claw (odontus); PF, palpal femur; PG, palpal genu; PL, posterolateral scutal seta; pST, parasubterminala (z); PT', pretarsala I ( $\zeta)$; PT”,

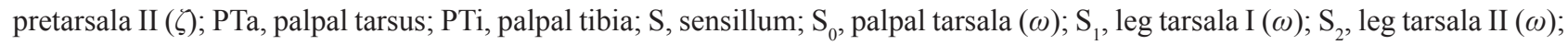

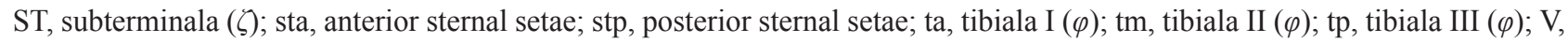
ventral idiosomal setae; u, uropore (anus). Scale bars: $50 \mu \mathrm{m}$ (A-E), $100 \mu \mathrm{m}$ (F, G), $50 \mu \mathrm{m}$ (H, I), $50 \mu \mathrm{m}$ (J-L).

\section{Leptotrombidium globosum (Schluger, 1960)}

\section{(Figs. 3-5)}

Trombicula (Leptotrombidium) globosa Schluger, 1960 (in Schluger et al. 1960b): 1796, fig. 5.

Leptotrombidium (Leptotrombidium) globosum: Lakshana 1973: 7; Vercammen-Grandjean \& Langston 1976: 337, pl. 55; Kudryashova 2004: 19; Chau et al. 2007: 47, fig. 19.

Leptotrombidium globosum: Stekolnikov 2013: 119; 2021: 117.

TABLE 2. Morphometric (AW-Ip, $\mu \mathrm{m}$ ) and meristic (DS-NDV) traits of Leptotrombidium globosum (Schluger, 1960) $(n=4)$.

\begin{tabular}{|c|c|c|c|}
\hline & Range & Mean & Lectotype \\
\hline AW & $64-68$ & 66 & 66 \\
\hline PW & $74-77$ & 76 & 76 \\
\hline SB & $30-33$ & 32 & 33 \\
\hline ASB & $32-33$ & 33 & 33 \\
\hline PSB & $15-16$ & 15 & 15 \\
\hline SD & $46-49$ & 48 & 49 \\
\hline P-PL & $16-19$ & 17 & 17 \\
\hline AP & $26-30$ & 28 & 30 \\
\hline $\mathrm{AM}$ & $52-56$ & 54 & 53 \\
\hline $\mathrm{AL}$ & $44-47$ & 45 & 47 \\
\hline PL & $56-61$ & 58 & 61 \\
\hline $\mathrm{H}$ & $60-65$ & 63 & 65 \\
\hline $\mathrm{D}_{\min }$ & $35-41$ & 40 & 35 \\
\hline $\mathrm{D}_{\max }$ & $53-58$ & 57 & 53 \\
\hline $\mathrm{V}_{\min }$ & $24-29$ & 26 & 24 \\
\hline $\mathrm{V}_{\max }$ & $44-50$ & 48 & 50 \\
\hline pa & $250-276$ & 264 & 265 \\
\hline $\mathrm{pm}$ & $222-223$ & 222 & 223 \\
\hline $\mathrm{pp}$ & $244-278$ & 267 & 270 \\
\hline Ip & $746-776$ & 760 & 758 \\
\hline DS & $85-90$ & 88 & 90 \\
\hline V & $67-73$ & 69 & 67 \\
\hline NDV & $152-162$ & 157 & 157 \\
\hline
\end{tabular}


Diagnosis. $\mathrm{SIF}=7 \mathrm{~B}-\mathrm{B}-3-2111.0000 ; \mathrm{fsp}=7.7 .7 ; \mathrm{fCx}=1.1 .1 ; \mathrm{fSt}=2.2 ; \mathrm{fPp}=\mathrm{N} / \mathrm{N} / \mathrm{BNN} ; \mathrm{fSc}: \mathrm{PL}>\mathrm{AM}>\mathrm{AL} ; \mathrm{Ip}=$ 746-776; fD = 2H-(10-12)-(15-22)+(53-61); DS = 85-90; V =67-73; NDV = 152-162. Standard measurements of type series given in Table 2.

Description (larva) (based on lectotype and 3 paralectotypes, fD recorded in three specimens). IDIOSOMA (Figs. 3A, 4B-G). Eyes $2+2$; 85-90 barbed dorsal idiosomal setae, including one pair of humeral setae, 10-12 setae in $1^{\text {st }}$ posthumeral row (C except humeral setae), 15-22 setae in $2^{\text {nd }}$ posthumeral row (D) plus 53-61 setae with unclear distribution by rows (sometimes $3^{\text {rd }}$ row, E, with 26-28 setae, recognized); 4 sternal setae; 67-73 ventral setae; NDV = 152-162.

GNATHOSOMA (Fig. 5A, B). Cheliceral blade with tricuspid cap; gnathobase covered with puncta and bears 1 pair of branched gnathocoxal (tritorostral) setae; cheliceral base and palpal femur covered with puncta; galeal (deutorostral) seta branched; palpal claw with 3 prongs; setae on palpal femur and genu nude; dorsal palpal tibial seta branched, lateral and ventral palpal tibial setae nude; palpal tarsus with 7 branched setae and tarsala $(\omega)$.

SCUTUM (Figs. 3, 4A). Nearly rectangular, moderately covered with rather large puncta, posterior margin broadly rounded; AM posterior to level of AL, sensillary (trichobothrial) bases at level of PL or slightly posterior (P-PL - PSB $=1-3 \mu \mathrm{m})$; all scutal setae barbed similarly to dorsal idiosomal setae; PL $\geq$ AM $>$ AL; flagelliform sensilla (trichobothria), with about 7-8 long branches in distal half.

LEGS (Fig. 5C-E). All 7-segmented, with 1 pair of claws and claw-like empodium. Leg I: coxa with 1 branched seta (1B); trochanter 1B; basifemur 1B; telofemur 5B; genu 4B, 2 genualae $(\sigma)$, microgenuala $(\kappa)$; tibia 8B, 2 tibialae $(\varphi)$, microtibiala $(\kappa)$; tarsus 22B, tarsala $(\omega)$, microtarsala $(\varepsilon)$ distal to tarsala, subterminala $(\zeta)$, parasubterminala $(z)$,

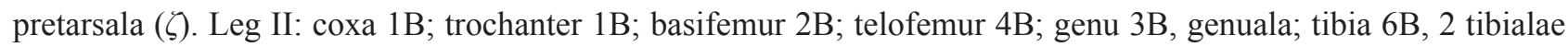
$(\varphi)$; tarsus $16 \mathrm{~B}$, tarsala $(\omega)$, microtarsala $(\varepsilon)$ posterior to tarsala, pretarsala $(\zeta)$. Leg III: coxa 1B; trochanter 1B; basifemur 2B; telofemur 3B; genu 3B, genuala; tibia 6B, tibiala; tarsus 15B.

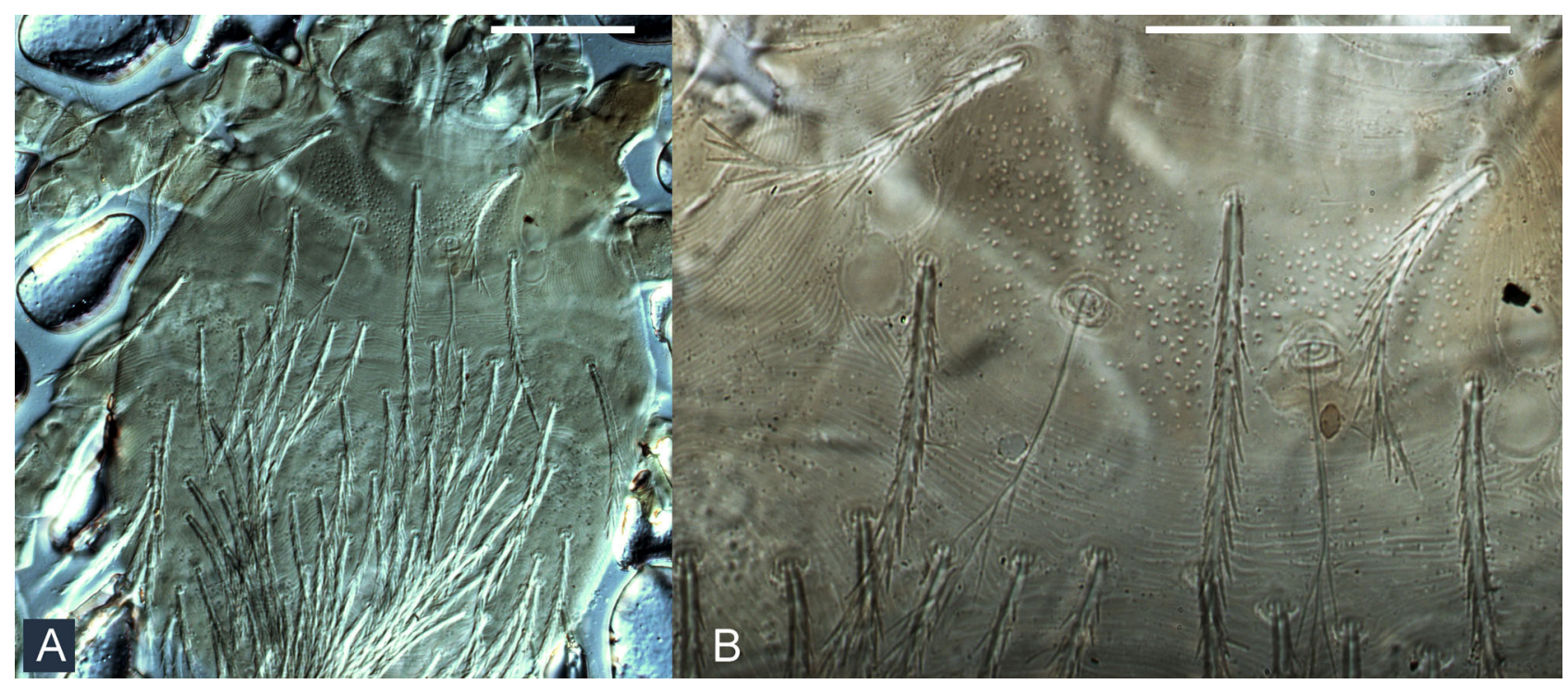

FIGURE 3. Leptotrombidium globosum (Schluger, 1960). A, dorsal aspect of idiosoma in paralectotype ZMMU Tdt-3275, specimen 4; B, scutum of lectotype. Scale bars: $50 \mu \mathrm{m}$.

Distribution and hosts. This species was described from North Vietnam, Quang Ninh Province, ex Leopoldamys sabanus (Thomas) (= Rattus sabanus) (Schluger et al. 1960b). Vercammen-Grandjean \& Langston (1976) added to the list of hosts Leopoldamys edwardsi (Thomas) [= Rattus grochovskiae D. Tien (nomen nudum)] and Tupaia belangeri chinensis (Anderson) (= T. glis modesta), based on examination of syntypes. Later it was also recorded from Thailand, ex Mus sp., Niviventer niviventer (= Rattus niviventer), and T. glis (Lakshana 1973).

Type material examined. Lectotype larva (ZMMU Tdt-3276, specimen 4, designated here) ex L. edwardsi [labeled as Rattus sp. and R. grochovskii (nomen nudum)] No 36, VIETNAM: Quang Ninh Province, Ha Lam District, Ha Long (= Hon Gai), 2 February 1956, coll. I.M. Grochovskaja. Three paralectotypes larvae (ZMMU Tdt3260, specimen 1; ZMMU Tdt-3261, specimen 1; ZMMU Tdt-3262, specimen 5) with same data as lectotype.

Remarks. Leptotrombidium globosum belongs to the magnum species group, which includes, in total, 15 species (Stekolnikov 2013). It differs from L. magnum (Schluger, 1960) (and two species synonymized with it in 
the present paper, L. dooleyi Nadchatram, 1970 and L. submagnum Wang, Li and Shi, 1988) in having the posterior scutal margin evenly rounded from the level of PL vs. greatly projected posterior to PL and straight in the middle part, the lesser number of setae in $1^{\text {st }}$ posthumeral row (10-12 vs. 14-17), greater NDV (152-162 vs. 118-130); smaller scutum (PW 74-77, SB 30-33, and SD 46-49 vs. 79-89, 33-39, and 51-58, respectively); PL > AM vs. AM $\geq$ PL, and shorter legs (Ip $=746-776$ vs. 851-946).

Leptotrombidium globosum differs from L. keukenschrijveri (Walch, 1924) in having the evenly rounded posterior margin of scutum (vs. slightly bilobate and concave in center); by PL > AM vs. AM > PL; by greater NDV (152-162 vs. 114), by $10-12$ setae in $1^{\text {st }}$ posthumeral row vs. $16(8+8)$, and by larger scutum (AW 64-68, PW 74-77, and SD 46-49 vs. 59-61, 69-72, and 38-41, respectively).

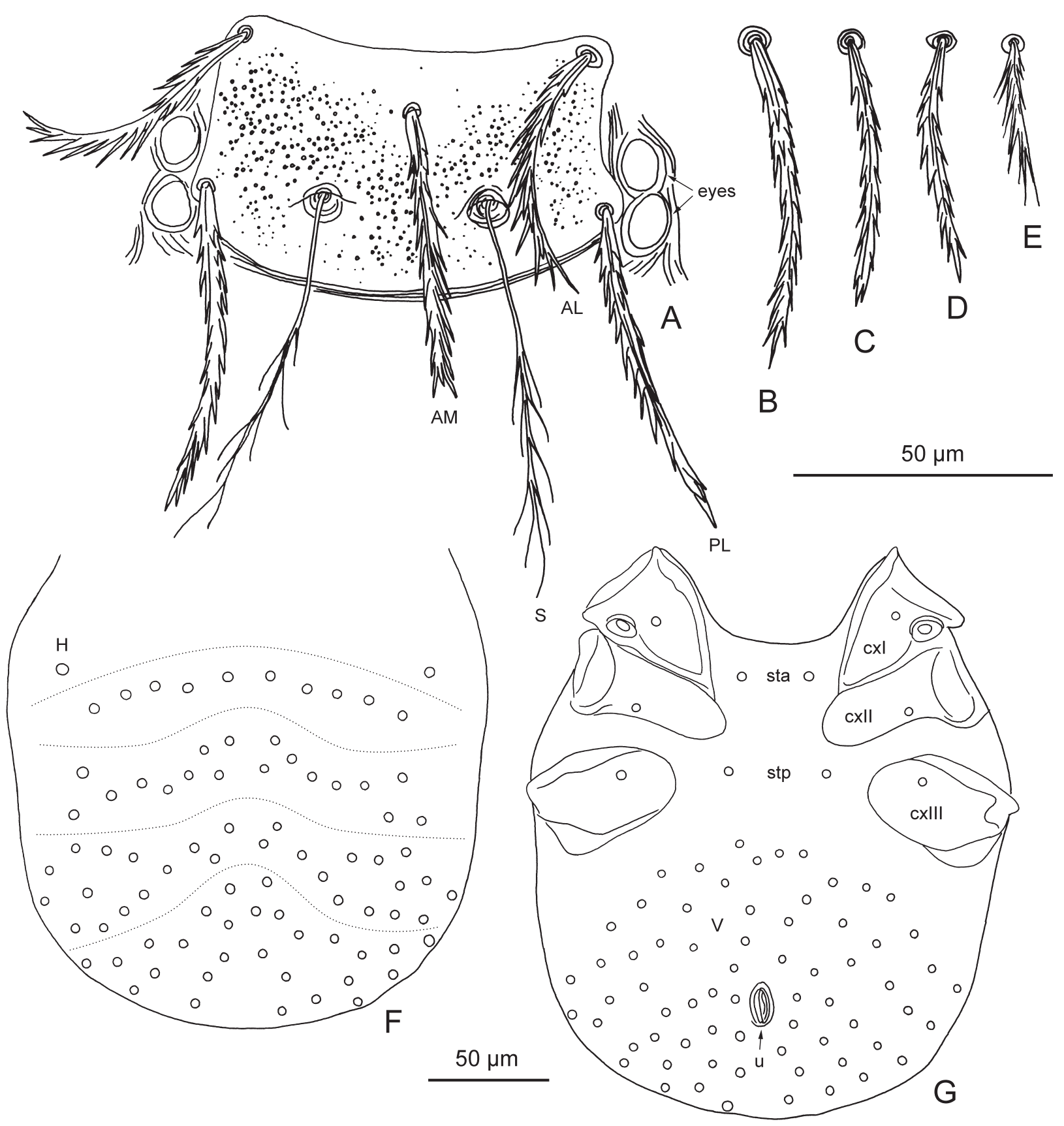

FIGURE 4. Leptotrombidium globosum (Schluger, 1960). A, scutum of lectotype; B, humeral seta (C antero-marginal) of lectotype; C, dorsal idiosomal seta of lectotype; D, postanal seta of lectotype; E, preanal seta of lectotype; F, arrangement of dorsal idiosomal setae in paralectotype ZMMU Tdt-3260, specimen 1; G, ventral aspect of idiosoma in paralectotype ZMMU Tdt-3260, specimen 1. Abbreviations as in Fig. 2. Scale bars: $50 \mu \mathrm{m}$ (A-E), $50 \mu \mathrm{m}$ (F, G). 

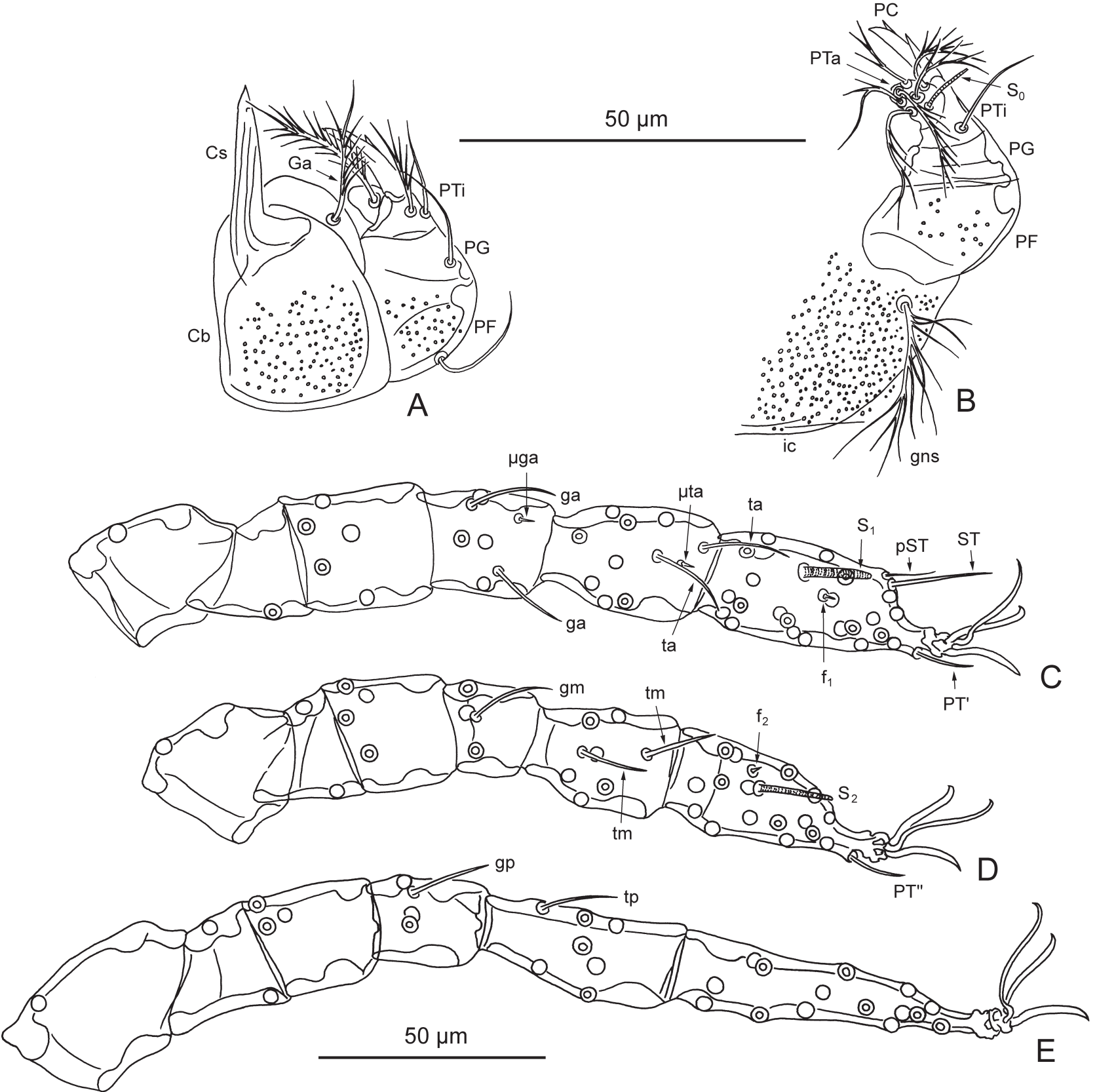

FIGURE 5. Leptotrombidium globosum (Schluger, 1960). A, dorsal aspect of gnathosoma of lectotype; B, ventral aspect of gnathosoma of lectotype; C, leg I (trochanter-tarsus) of paralectotype ZMMU Tdt-3260, specimen 1; D, leg II (trochanter-tarsus) of paralectotype ZMMU Tdt-3260, specimen 1; E, leg III (trochanter-tarsus) of paralectotype ZMMU Tdt-3260, specimen 1. Abbreviations as in Fig. 2. Scale bars: $50 \mu \mathrm{m}(\mathrm{A}, \mathrm{B}), 50 \mu \mathrm{m}(\mathrm{C}-\mathrm{E})$.

Remaining species of the magnum group were described in 1980s-1990s in China (L. arctonycis Xiang and Wen, 1984, L. baoshui Wen and Xiang, 1984, L. biji Wen and Xiang, 1984, L. caudatum Wen, Zhou, Chen, Wang and Zhang, 1984, L. huangchuanense Yang, 1994, L. kunshui Wen and Xiang, 1984, L. shuiqui Liao and Yuan, 1998, L. shuminense Zhang, Deng and Wang, 1996, L. sixinum Wen, Zhou, Chen, Wang and Zhang, 1984, and L. xianglinense Wen, 1984). Two of them, L. arctonycis and L. xianglinense, are known only from the holotypes. Differences of all these species from L. globosum, L. magnum, and L. keukenschrijveri require further investigation.

Among these species from China, $L$. sixinum is the most probable candidate for the synonymization with $L$. globosum. The former species differs from L. globosum in PW 83-85 vs. 74-77, AM $\geq$ PL vs. PL > AM, lesser NDV (132 vs. 152-162), and in slightly longer legs (Ip 835 vs. 746-776). Statistical and taxonomic significance of these differences can not be estimated without a direct comparison of the type series. Two other species, $L$. biji and $L$. 
caudatum, are also similar to L. globosum by the shape of scutum, but differ in its greater size (in L. biji, AW 70-80, PW 85-103, AP 33-38; in L. caudatum, AW 73-79, PW 85-88, ASB 35-42; in L. globosum, AW 64-68, PW 74-77, ASB 32-33, AP 26-30) and in AM $\geq$ PL vs. PL > AM. Leptotrombidium biji also differs from L. globosum in much longer legs (Ip 1015-1049 vs. 746-776); L. caudatum has longer setae (AM 64-75, AL 48-56, PL 65-72, H 73-75 vs. 52-56, 44-47, 56-61, and 60-65, respectively) and lesser NDV (116 vs. 152-162).

\section{Leptotrombidium gracipalpe (Schluger, 1960)}

(Figs. 6, 7)

Trombicula (Leptotrombidium) gracipalpis Schluger, 1960 (in Schluger et al. 1960b): 1793, fig. 3.

Leptotrombidium (Leptotrombidium) gracipalpe: Vercammen-Grandjean \& Langston 1976: 520, pl. 137; Kudryashova 2004: 19; Chau et al. 2007: 48, fig. 20.

Leptotrombidium gracipalpe: Stekolnikov 2013: 80; 2021: 117.

Diagnosis. $\mathrm{SIF}=7 \mathrm{~B}-\mathrm{B}-3-2111.0000 ; \mathrm{fsp}=7.7 .7 ; \mathrm{fCx}=1.1 .1 ; \mathrm{fSt}=2.2 ; \mathrm{fPp}=\mathrm{N} / \mathrm{B} / \mathrm{BNN}$; $\mathrm{fSc}: \mathrm{PL}>\mathrm{AM}>\mathrm{AL} ; \mathrm{Ip}$ $=574-643 ; \mathrm{fD}=2 \mathrm{H}-8-6-6-4(6)-4 ; \mathrm{DS}=30-32 ; \mathrm{V}=24-38 ; \mathrm{NDV}=56-68$. Standard measurements of type series given in Table 3.

TABLE 3. Morphometric (AW-Ip, $\mu \mathrm{m}$ ) and meristic (DS-NDV) traits of Leptotrombidium gracipalpe (Schluger, 1960) $(\mathrm{n}=13)$.

\begin{tabular}{llll}
\hline & Range & Mean & Lectotype \\
\hline $\mathrm{AW}$ & $55-63$ & 58 & 55 \\
$\mathrm{PW}$ & $62-67$ & 64 & 63 \\
$\mathrm{SB}$ & $27-32$ & 29 & 28 \\
$\mathrm{ASB}$ & $13-25$ & 22 & 22 \\
$\mathrm{PSB}$ & 13 & 12 \\
$\mathrm{SD}$ & $12-17$ & 36 & 33 \\
$\mathrm{P}-\mathrm{PL}$ & $33-38$ & 16 & 16 \\
$\mathrm{AP}$ & $14-19$ & 18 & 16 \\
$\mathrm{AM}$ & $16-20$ & 43 & 43 \\
$\mathrm{AL}$ & $33-59$ & 35 & 35 \\
$\mathrm{PL}$ & $33-38$ & 65 & 66 \\
$\mathrm{H}$ & $59-68$ & 56 & 56 \\
$\mathrm{D}_{\min }$ & $53-59$ & 40 & 40 \\
$\mathrm{D}_{\max }$ & $36-44$ & 59 & 63 \\
$\mathrm{~V}_{\min }$ & $55-64$ & 23 & 24 \\
$\mathrm{~V}_{\max }$ & $21-25$ & 46 & 42 \\
pa & $40-53$ & 214 & 195 \\
pm & $195-229$ & 182 & 181 \\
$\mathrm{pp}$ & $172-199$ & 213 & 198 \\
$\mathrm{Ip}$ & $196-227$ & 614 & 574 \\
$\mathrm{DS}$ & $574-643$ & 31 & 30 \\
$\mathrm{~V}$ & $30-32$ & 30 & 38 \\
$\mathrm{NDV}$ & $24-38$ & 61 & 68 \\
\hline
\end{tabular}




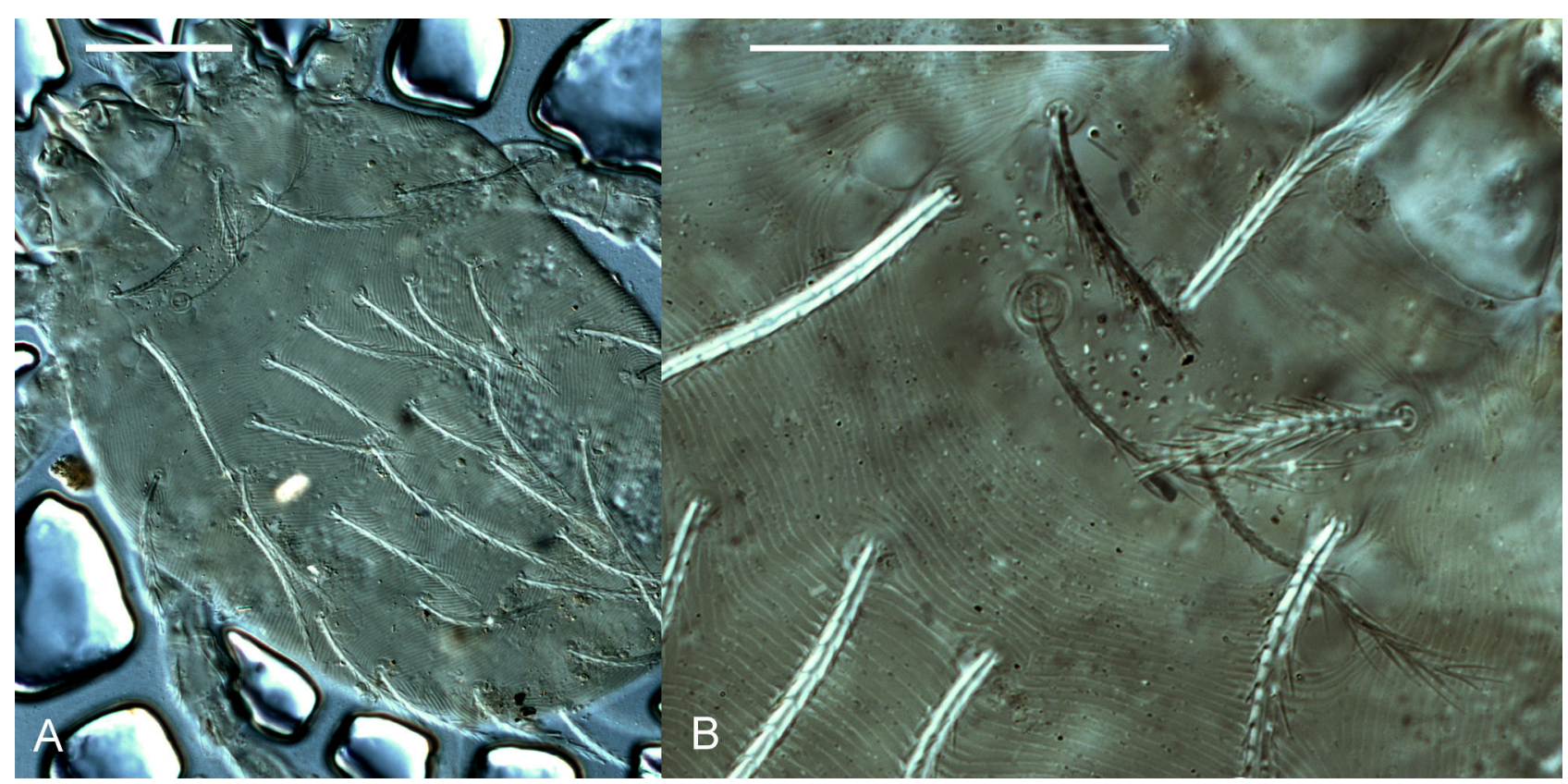

FIGURE 6. Leptotrombidium gracipalpe (Schluger, 1960), lectotype. A, dorsal aspect of idiosoma; B, scutum. Scale bars: 50 $\mu \mathrm{m}$.

Description (larva) (based on lectotype and 12 paralectotypes, fD recorded in four specimens). IDIOSOMA (Figs. 6A, 7B-G). Eyes $2+2 ; 30-32$ barbed dorsal idiosomal setae, including one pair of humeral setae, with distribution by rows $2 \mathrm{H}-8-6-6-4(6)-4 ; 4$ sternal setae; $24-38$ ventral setae; NDV $=56-68$.

GNATHOSOMA (Fig. 7H, I). Cheliceral blade with tricuspid cap; gnathobase covered with puncta and bears 1 pair of branched gnathocoxal (tritorostral) setae; cheliceral base covered with puncta; galeal (deutorostral) seta branched; palpal claw with 3 prongs; seta on palpal femur nude, seta on palpal genu branched, dorsal palpal tibial seta branched, lateral and ventral palpal tibial setae nude; palpal tarsus with 7 branched setae and tarsala $(\omega)$.

SCUTUM (Figs. 6, 7A). Rectangular, moderately covered with rather large puncta, greatly projected posterior to $\mathrm{PL}$, posterior margin almost straight in middle part; AM posterior to level of AL, sensillary (trichobothrial) bases posterior to level of PL (P-PL - PSB $=1-5 \mu \mathrm{m}$ ); all scutal setae barbed similarly to dorsal idiosomal setae; PL > $\mathrm{AM}>\mathrm{AL}$; flagelliform sensilla (trichobothria) densely covered with small cilia in proximal half and with about 11 long branches in distal half.

LEGS (Fig. 7J-L). All 7-segmented, with 1 pair of claws and claw-like empodium. Leg I: coxa with 1 branched seta (1B); trochanter 1B; basifemur 1B; telofemur 5B; genu 4B, 2 genualae $(\sigma)$, microgenuala $(\kappa)$; tibia 8B, 2 tibialae $(\varphi)$, microtibiala $(\kappa)$; tarsus 22B, tarsala $(\omega)$, microtarsala $(\varepsilon)$ distal to tarsala, subterminala $(\zeta)$, parasubterminala $(z)$,

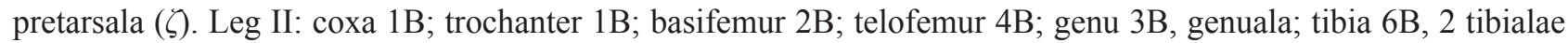

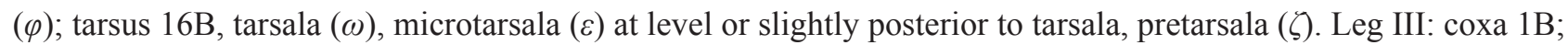
trochanter 1B; basifemur 2B; telofemur 3B; genu 3B, genuala; tibia 6B, tibiala; tarsus 15B.

Distribution and hosts. This species was described from North Vietnam, Quang Ninh Province, ex Leopoldamys sabanus, Rattus tanezumi Temminck (= R. rattus tikos), and Tupaia belangeri chinensis (= T. glis modesta) (Schluger et al. 1960b).

Type material examined. Lectotype larva (ZMMU Tdt-3270, specimen 4, designated here) ex Tupaia belangeri chinensis (labeled as T. glis and T. ferruginea) No 29, VIETNAM: Quang Ninh Province, Ha Lam District, Ha Long (= Hon Gai), 1 February 1956, coll. I.M. Grochovskaja. Twelve paralectotypes larvae (ZMMU Tdt-3270, specimen 2; ZMMU Tdt-3271, specimens 3, 5; ZMMU Tdt-3272, specimen 2; ZMMU Tdt-3273, specimens 1, 3, 4, 5; ZMMU Tdt-3274, specimens 1, 4; ZMMU Tdt-3275, specimen 5; ZMMU Tdt-3266, specimen 6) with same data as lectotype.

Remarks. Leptotrombidium gracipalpe belongs to the orientale group, which includes, in total, 17 species (Stekolnikov 2013). This species is unique in its palpal formula $\mathrm{fPp}=\mathrm{N} / \mathrm{B} / \mathrm{BNN}$, i.e. the palpal genual seta is branched that is opposed to all other members of the group and to the overwhelming majority of other Leptotrombidium species. 

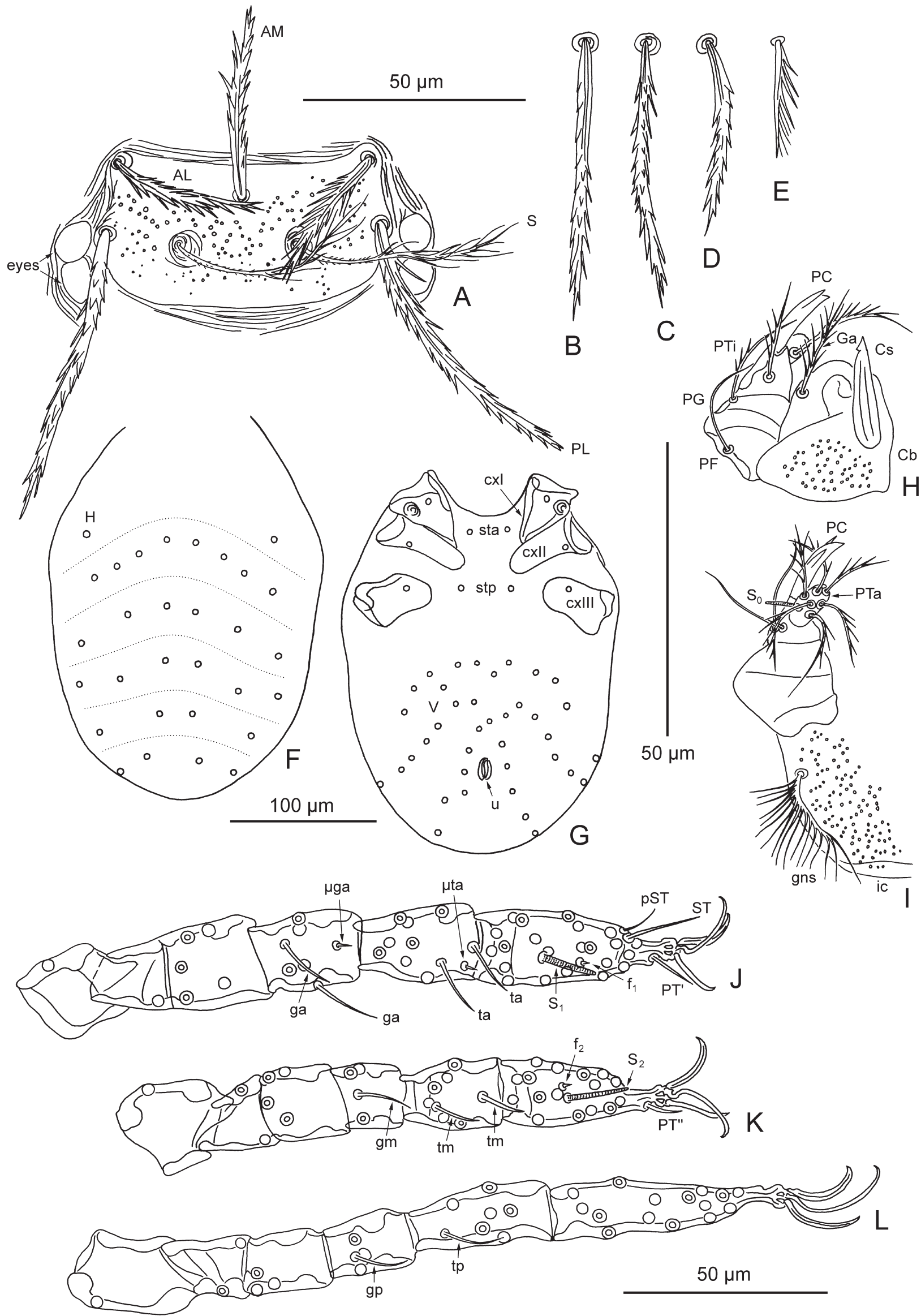
FIGURE 7. Leptotrombidium gracipalpe (Schluger, 1960). A, scutum of lectotype; B, humeral seta (C antero-marginal) of lectotype; C, dorsal idiosomal seta of lectotype; D, postanal seta of lectotype; $\mathbf{E}$, preanal seta of lectotype; F, arrangement of dorsal idiosomal setae of lectotype; $\mathbf{G}$, ventral aspect of idiosoma of lectotype; $\mathbf{H}$, dorsal aspect of gnathosoma in paralectotype ZMMU Tdt-3272, specimen 2; I, ventral aspect of gnathosoma in paralectotype ZMMU Tdt-3272, specimen 2; J, leg I (trochanter-tarsus) in paralectotype ZMMU Tdt-3266, specimen 6; K, leg II (trochanter-tarsus) in paralectotype ZMMU Tdt3266, specimen 6; L, leg III (trochanter-tarsus) in paralectotype ZMMU Tdt-3266, specimen 6. Abbreviations as in Fig. 2. Scale bars: $50 \mu \mathrm{m}(\mathrm{A}-\mathrm{E}), 100 \mu \mathrm{m}(\mathrm{F}, \mathrm{G}), 50 \mu \mathrm{m}(\mathrm{H}, \mathrm{I}), 50 \mu \mathrm{m}(\mathrm{J}-\mathrm{L})$.

\section{Leptotrombidium horridum (Schluger, 1960)}

(Figs. 8-10)

Trombicula (Leptotrombidium) horrida Schluger, 1960 (in Schluger et al. 1960b): 1790, fig. 1.

Leptotrombidium (Leptotrombidium) horridum: Vercammen-Grandjean \& Langston 1976: 560, pl. 152.

Leptotrombidium horridum: Stekolnikov 2013: 88; 2021: 118.

Diagnosis. $\mathrm{SIF}=7 \mathrm{~B}-\mathrm{B}-3-2111.0000 ; \mathrm{fsp}=7.7 .7 ; \mathrm{fCx}=1.1 .1 ; \mathrm{fSt}=2.2 ; \mathrm{fPp}=\mathrm{N} / \mathrm{N} / \mathrm{BNN} ; \mathrm{fSc}: \mathrm{PL}>\mathrm{AM}>\mathrm{AL} ; \mathrm{Ip}$ $=851-990 ; \mathrm{fD}=2 \mathrm{H}-(9-11)-8-(7-11)-6+(8-12) ; \mathrm{DS}=42-48 ; \mathrm{V}=38-46 ; \mathrm{NDV}=83-93$. Standard measurements of type series given in Table 4.

Description (larva) (based on lectotype and 24 paralectotypes, fD recorded in four specimens). IDIOSOMA (Figs. 8A, 9B-G). Eyes 2 + 2; 42-48 barbed dorsal idiosomal setae, including one pair of humeral setae, 9-11 setae in $1^{\text {st }}$ posthumeral row (C except humeral setae), 8 setae in $2^{\text {nd }}$ row (D), 7-11 setae in $3^{\text {rd }}$ row (E), 6 setae in $4^{\text {th }}$ row (F) plus 8-12 caudal setae; 4 sternal setae; 38-46 ventral setae; NDV $=83-93$.

GNATHOSOMA (Fig. 10A, B). Cheliceral blade with tricuspid cap; gnathobase covered with puncta and bears 1 pair of branched gnathocoxal (tritorostral) setae; cheliceral base and palpal femur covered with puncta, palpal genu with few puncta; galeal (deutorostral) seta branched; palpal claw with 3 prongs; setae on palpal femur and genu nude, dorsal palpal tibial seta branched, lateral and ventral palpal tibial setae nude; palpal tarsus with 7 branched setae and tarsala $(\omega)$.

SCUTUM (Figs. 8, 9A). Rectangular, moderately covered with rather large puncta, greatly projected posterior to PL, posterior margin slightly concave in middle part; AM posterior to level of AL, sensillary (trichobothrial) bases at level of PL or slightly posterior (P-PL $-\mathrm{PSB}=0-6 \mu \mathrm{m})$; all scutal setae barbed similarly to dorsal idiosomal setae; $\mathrm{PL} \geq \mathrm{AM}>\mathrm{AL}$; flagelliform sensilla (trichobothria) with about 7 branches in distal half.

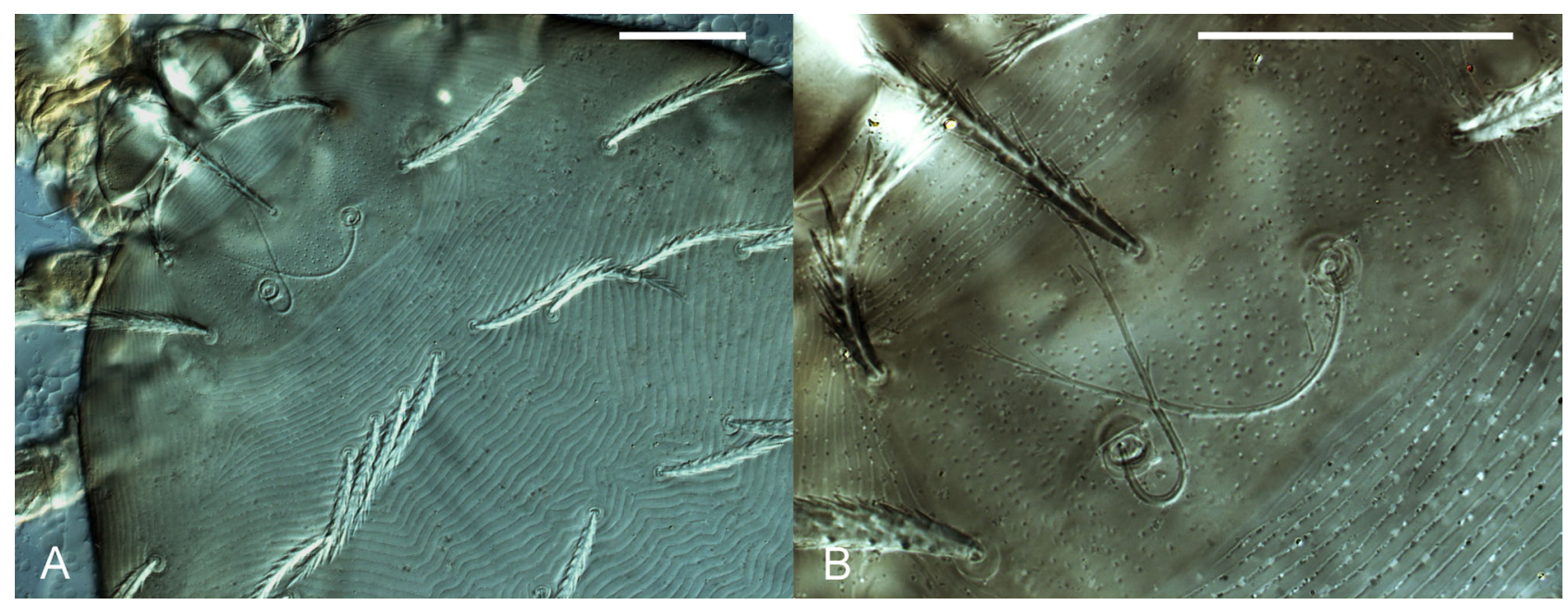

FIGURE 8. Leptotrombidium horridum (Schluger, 1960), lectotype. A, dorsal aspect of idiosoma; B, scutum. Scale bars: 50 $\mu \mathrm{m}$. 
TABLE 4. Morphometric (AW-Ip, $\mu \mathrm{m})$ and meristic (DS-NDV) traits of Leptotrombidium horridum (Schluger, 1960) $(n=25)$.

\begin{tabular}{llll}
\hline & Range & Mean & Lectotype \\
\hline $\mathrm{AW}$ & $82-96$ & 86 & 88 \\
$\mathrm{PW}$ & $95-105$ & 100 & 102 \\
$\mathrm{SB}$ & $40-47$ & 43 & 43 \\
$\mathrm{ASB}$ & $32-42$ & 37 & 37 \\
$\mathrm{PSB}$ & $18-23$ & 20 & 21 \\
$\mathrm{SD}$ & $53-63$ & 58 & 58 \\
$\mathrm{P}-\mathrm{PL}$ & $21-27$ & 23 & 23 \\
$\mathrm{AP}$ & $29-35$ & 32 & 32 \\
$\mathrm{AM}$ & $56-67$ & 61 & 57 \\
$\mathrm{AL}$ & $43-54$ & 50 & 52 \\
$\mathrm{PL}$ & $60-70$ & 66 & 70 \\
$\mathrm{H}$ & $64-80$ & 73 & 78 \\
$\mathrm{D}_{\min }$ & $41-54$ & 45 & 44 \\
$\mathrm{D}_{\max }$ & $64-74$ & 70 & 74 \\
$\mathrm{~V}_{\min }$ & $27-37$ & 31 & 28 \\
$\mathrm{~V}_{\max }$ & $52-65$ & 56 & 65 \\
pa & $285-342$ & 315 & 328 \\
pm & $246-288$ & 271 & 280 \\
pp & $304-362$ & 333 & 342 \\
$\mathrm{Ip}$ & $851-990$ & 922 & 950 \\
$\mathrm{DS}$ & $42-48$ & 46 & 42 \\
$\mathrm{~V}$ & $38-46$ & 42 & 41 \\
$\mathrm{NDV}$ & $83-93$ & 88 & 83 \\
\hline
\end{tabular}

LEGS (Fig. 10C-E). All 7-segmented, with 1 pair of claws and claw-like empodium. Leg I: coxa with 1 branched seta (1B); trochanter 1B; basifemur 1B; telofemur 5B; genu 4B, 2 genualae $(\sigma)$, microgenuala $(\kappa)$; tibia $8 \mathrm{~B}, 2$ tibialae $(\varphi)$, microtibiala $(\kappa)$; tarsus $22 \mathrm{~B}$, tarsala $(\omega)$, microtarsala $(\varepsilon)$ distal to tarsala, subterminala $(\zeta)$, parasubterminala $(z)$,

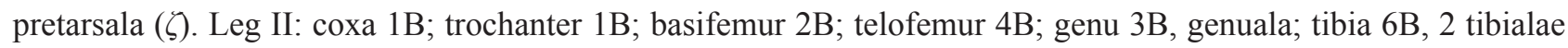
$(\varphi)$; tarsus 16B, tarsala $(\omega)$, microtarsala $(\varepsilon)$ posterior to tarsala, pretarsala $(\zeta)$. Leg III: coxa 1B; trochanter 1B; basifemur 2B; telofemur 3B; genu 3B, genuala; tibia 6B, tibiala; tarsus 14B.

Distribution and hosts. This species was described from North Vietnam, Quang Ninh Province, ex Leopoldamys sabanus (= Rattus sabanus) and Tupaia belangeri chinensis (= T. glis modesta) (Schluger et al. 1960b). VercammenGrandjean \& Langston (1976) added also Leopoldamys edwardsi (Thomas) [= Rattus grochovskiae (nomen nudum)] and Tupaia glis (= T. ferruginea) to the list of hosts, on the base of examination of syntypes.

Type material examined. Lectotype larva (ZMMU L. horridum_04, specimen 5, designated here) ex Leopoldamys edwardsi [labeled as R. grochovskii (nomen nudum)] No 36, VIETNAM: Quang Ninh Province, Ha Lam District, Ha Long (= Hon Gai), 2 February 1956, coll. I.M. Grochovskaja. Eight paralectotypes larvae (ZMMU L. horridum_01, specimens 1-3; ZMMU L. horridum_06, specimen 2; ZMMU L. horridum_08, specimens 4, 5; ZMMU L. horridum_09, specimens 2, 5; ZMMU Tdt-3248, specimen 2) ex L. edwardsi [labeled as R. grochovskii (nomen nudum)] No 40, 3 February 1956, other data same as for lectotype; three paralectotypes larvae (ZMMU Tdt-3245, specimen 5; ZMMU Tdt-3246, specimens 2, 3) ex Tupaia belangeri [labeled as T. glis and T. hongaiensis (nomen nudum)] No 42, 3 February 1956, other data same; one paralectotype larva (ZMMU Tdt-3249, specimen 2) ex L. edwardsi [labeled as Rattus sp. and R. grochovskii (nomen nudum)] No 44, 6 February 1956, other data same; one paralectotype larva (ZMMU Tdt-3250, specimen 4) ex L. edwardsi [labeled as Rattus sp. and R. grochovskii (nomen nudum)] No 45, 6 February 1956, other data same; five paralectotypes larvae (ZMMU Tdt-3260, specimen 2; ZMMU Tdt-3261, specimens 3, 4, 6; ZMMU Tdt-3262, specimen 1) with same data as lectotype; five paralectotypes 
larvae (ZMMU Tdt-3264, specimen 4; ZMMU Tdt-3265, specimens 3, 5; ZMMU Tdt-3268, specimen 5; ZMMU Tdt-3272, specimen 3) ex Tupaia belangeri (labeled as T. glis and T. ferruginea) No 29, 1 February 1956, other data same.
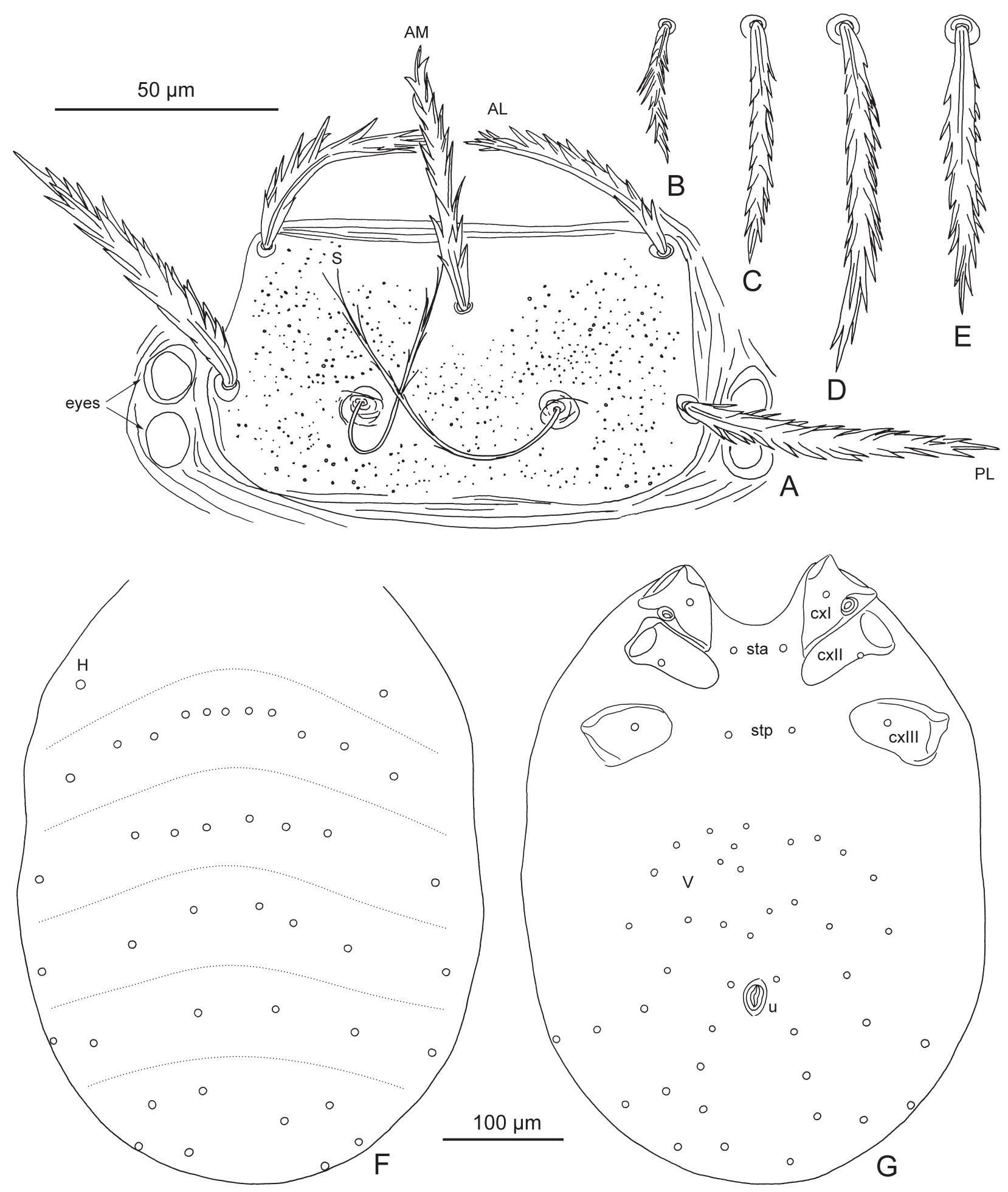

FIGURE 9. Leptotrombidium horridum (Schluger, 1960), lectotype. A, scutum; B, preanal seta; C, postanal seta; D, humeral seta (C antero-marginal); E, dorsal idiosomal seta; $\mathbf{F}$, arrangement of dorsal idiosomal setae; $\mathbf{G}$, ventral aspect of idiosoma. Abbreviations as in Fig. 2. Scale bars: $50 \mu \mathrm{m}(\mathrm{A}-\mathrm{E}), 100 \mu \mathrm{m}(\mathrm{F}, \mathrm{G})$. 

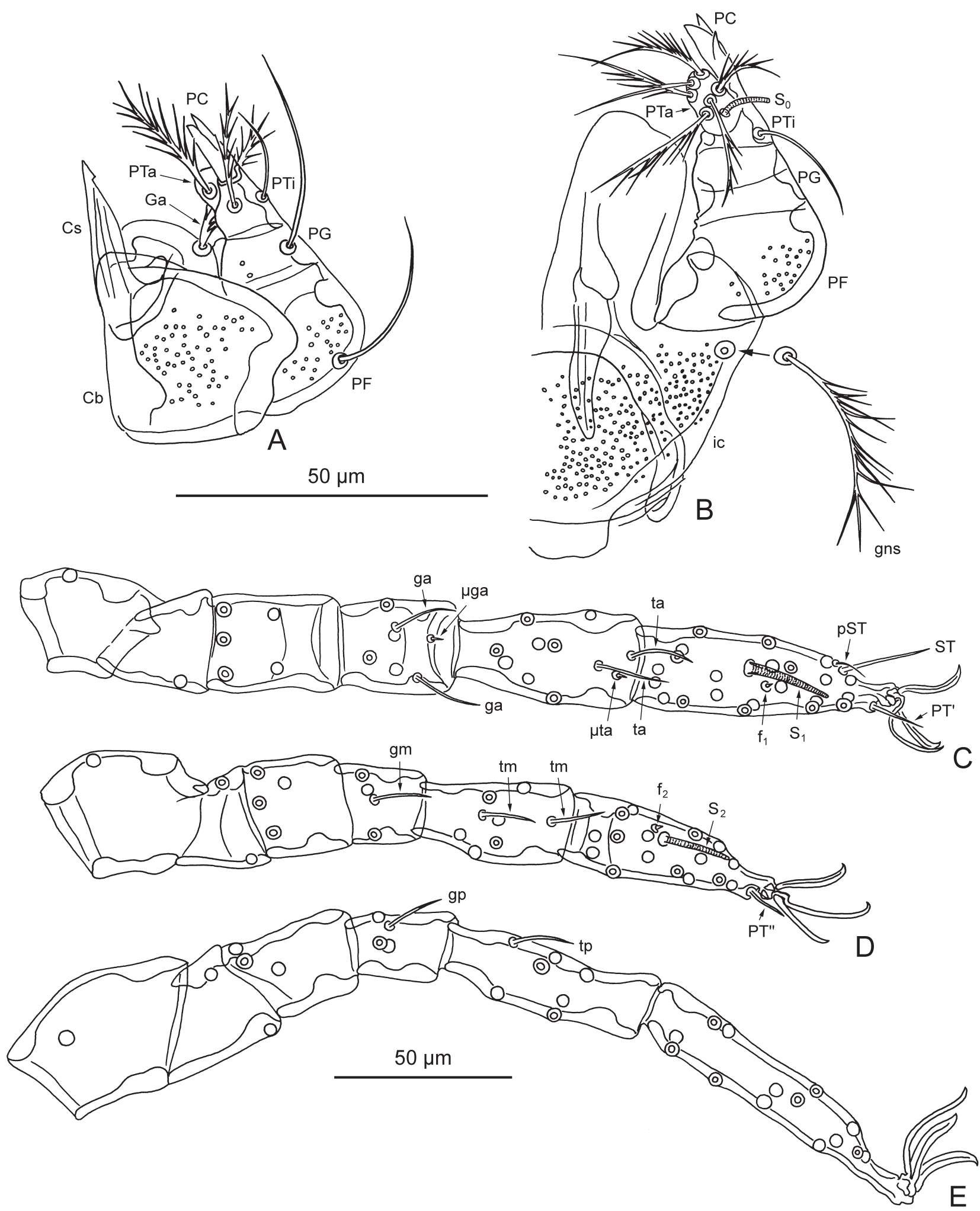

FIGURE 10. Leptotrombidium horridum (Schluger, 1960). A, dorsal aspect of gnathosoma of paralectotype ZMMU L. horridum 01, specimen 1; B, ventral aspect of gnathosoma of paralectotype ZMMU L. horridum_01, specimen 1. C, leg I (trochantertarsus) of lectotype; D, leg II (trochanter-tarsus) of lectotype; E, leg III (trochanter-tarsus) of lectotype. Abbreviations as in Fig. 2. Scale bars: $50 \mu \mathrm{m}(\mathrm{A}, \mathrm{B}), 50 \mu \mathrm{m}(\mathrm{C}-\mathrm{E})$.

Remarks. Leptotrombidium horridum belongs to the alopeciatum group, which includes five species (Stekolnikov 2013). It differs from L. spicatum Traub, 1960, L. baluense (Traub and Audy, 1954), and L. tupaianum 
Vercammen-Grandjean and Langston, 1976 in having the PL and dorsal idiosomal setae covered with usual uniform barbs vs. bearing 2-3 rows of short barbs and two lateral rows of large spikes. Leptotrombidium horridum differs from $L$. alopeciatum by the presence of nude ventral palpal tibial setae vs. branched ( $\mathrm{fPp}=\mathrm{N} / \mathrm{N} / \mathrm{BNN}$ vs. N/N/ BNB); by nearly doubled number of idiosomal setae (DS 42-48, V 38-46, and NDV 83-93 vs. 22, 22, and 44, respectively); by PL > AM vs. AM > PL; by sensillary bases situated at the level or posterior to SB vs. anterior; and by longer legs ( $\mathrm{Ip}=851-990$ vs. $718-745)$.

\section{Leptotrombidium magnum (Schluger, 1960)}

(Figs. 11-13)

Trombicula (Leptotrombidium) magna Schluger, 1960 (in Schluger et al. 1960b): 1796, fig. 4.

Leptotrombidium (Leptotrombidium) magnum: Lakshana 1973: 8; Vercammen-Grandjean \& Langston 1976: 332, pl. 52; Kudryashova 2004: 25.

Leptotrombidium magnum: Stekolnikov 2013: 120; 2021: 122.

Leptotrombidium dooleyi Nadchatram, 1970: 150, figs. 17-24, syn. nov.; Vercammen-Grandjean \& Langston 1976: 338, pl. 56; Stekolnikov 2013: 120.

Leptotrombidium (Leptotrombidium) submagnum Wang, Li and Shi, 1988: 140, figs. 9-12, syn. nov.; Li et al. 1997: 178, fig. 2-1-101; Stekolnikov 2013: 119.

Diagnosis. $\mathrm{SIF}=7 \mathrm{~B}-\mathrm{B}-3-2111.0000 ; \mathrm{fsp}=7.7 .7 ; \mathrm{fCx}=1.1 .1 ; \mathrm{fSt}=2.2 ; \mathrm{fPp}=\mathrm{N} / \mathrm{N} / \mathrm{BNN} ; \mathrm{fSc}: \mathrm{AM} \geq \mathrm{PL}>\mathrm{AL} ; \mathrm{Ip}$ $=851-946 ; \mathrm{fD}=2 \mathrm{H}-(14-15)-(12-17)-(17-18)-(10-11)-(6-8)+(4-9) ; \mathrm{DS}=71-74 ; \mathrm{V}=55-56 ; \mathrm{NDV}=126-130$. Standard measurements of type series given in Table 5.

Description (larva) (based on lectotype and 17 paralectotypes, fD recorded in two specimens). IDIOSOMA (Figs. 11A, 12B-G). Eyes 2+2; 71-74 barbed dorsal idiosomal setae, including one pair of humeral setae, 14-15 setae in $1^{\text {st }}$ posthumeral row (C except humeral setae), $12-17$ setae in $2^{\text {nd }}$ row (D), 17-18 setae in $3^{\text {rd }}$ row (E), $10-11$ setae in $4^{\text {th }}$ row $(\mathrm{F}), 6-8$ setae in $5^{\text {th }}$ row plus $4-9$ caudal setae; 4 sternal setae; $55-56$ ventral setae; NDV $=$ $126-130$.

GNATHOSOMA (Fig. 13A-C). Cheliceral blade with tricuspid cap; gnathobase covered with puncta and bears 1 pair of branched gnathocoxal (tritorostral) setae; cheliceral base and palpal femur covered with puncta; galeal (deutorostral) seta branched; palpal claw with 3 prongs; setae on palpal femur and genu nude, dorsal palpal tibial seta branched, lateral and ventral palpal tibial setae nude; palpal tarsus with 7 branched setae and tarsala $(\omega)$.

SCUTUM (Figs. 11, 12A). Rectangular, moderately covered with rather large puncta, greatly projected posterior to PL, posterior margin straight in middle part; AM posterior to level of AL, sensillary (trichobothrial) bases at level of PL or slightly posterior (P-PL $-\mathrm{PSB}=-5-4 \mu \mathrm{m}$ ); all scutal setae barbed similarly to dorsal idiosomal setae; AM $\geq \mathrm{PL}>\mathrm{AL}$; flagelliform sensilla (trichobothria) with about 5 branches in distal part.

LEGS (Fig. 13D-G). All 7-segmented, with 1 pair of claws and claw-like empodium. Leg I: coxa with 1 branched seta (1B); trochanter 1B; basifemur 1B; telofemur 5B; genu 4B, 2 genualae $(\sigma)$, microgenuala $(\kappa)$; tibia $8 \mathrm{~B}, 2$ tibialae $(\varphi)$, microtibiala $(\kappa)$; tarsus $22 \mathrm{~B}$, tarsala $(\omega)$, microtarsala $(\varepsilon)$ distal to tarsala, subterminala $(\zeta)$, parasubterminala $(z)$, pretarsala $(\zeta)$. Leg II: coxa 1B; trochanter 1B; basifemur 2B; telofemur 4B; genu 3B, genuala; tibia 6B, 2 tibialae $(\varphi)$; tarsus 16B, tarsala $(\omega)$, microtarsala $(\varepsilon)$ at level of tarsala, pretarsala $(\zeta)$. Leg III: coxa 1B; trochanter 1B; basifemur 2B; telofemur 3B; genu 3B, genuala; tibia 6B, tibiala; tarsus 15B.

Distribution and hosts. This species was described from North Vietnam, Quang Ninh Province, ex Rattus tanezumi Temminck (= R. rattus tikos), Leopoldamys sabanus (= Rattus sabanus) and Tupaia belangeri chinensis (= T. glis modesta) (Schluger et al. 1960b). Later it was recorded in Thailand, from birds Napothera macrodactyla (Strickland) and Stachyris poliocephala (Temminck) (Lakshana 1973). Vercammen-Grandjean \& Langston (1976) added also Tupaia glis ( $=$ T. ferruginea) to the list of hosts, based on examination of syntypes.

Leptotrombidium dooleyi was described from Nepal, Daman, ex field mouse (Apodemus sp.), and from Nepal, Bokaikunde, $23 \mathrm{~km}$ NE Trisuli, ex Rattus nitidus (Hodgson). Leptotrombidium submagnum was described from China, Hubei Province, Yichang County, Jiangjiamiao, ex Rattus losea (Swinhoe).

Type material examined. Lectotype larva (ZMMU Tdt-3268, specimen 3, designated here) ex Tupaia belangeri (labeled as T. glis and T. ferruginea) No 29, VIETNAM: Quang Ninh Province, Ha Lam District, Ha Long (= Hon Gai), 1 February 1956, coll. I.M. Grochovskaja. Five paralectotypes larvae (ZMMU Tdt-3262, specimen 3; ZMMU Tdt-3276, specimens 1, 2, 3, 5) ex L. edwardsi [labeled as Rattus sp. and R. grochovskii (nomen nudum)] No 36, 2 
February 1956, other data same; one paralectotype larva (ZMMU Tdt-3263, specimen 4) ex L. edwardsi [labeled as Rattus sp. and R. grochovskii (nomen nudum)] No 35, other data same; 11 paralectotypes larvae (ZMMU Tdt-3265, specimens 1, 4; ZMMU Tdt-3266, specimens 1, 2, 4; ZMMU Tdt-3267, specimen 5; ZMMU Tdt-3268, specimens 4, 6; ZMMU Tdt-3272, specimens 1, 4, 5) with same data as lectotype.

TABLE 5. Morphometric (AW-Ip, $\mu \mathrm{m}$ ) and meristic (DS-NDV) traits of Leptotrombidium magnum (Schluger, 1960) (n $=18$ ).

\begin{tabular}{llll}
\hline & Range & Mean & Lectotype \\
\hline $\mathrm{AW}$ & $69-79$ & 72 & 72 \\
$\mathrm{PW}$ & $79-89$ & 83 & 82 \\
$\mathrm{SB}$ & $33-39$ & 36 & 37 \\
$\mathrm{ASB}$ & $31-40$ & 36 & 34 \\
$\mathrm{PSB}$ & $15-22$ & 19 & 17 \\
$\mathrm{SD}$ & $51-58$ & 56 & 52 \\
$\mathrm{P}-\mathrm{PL}$ & $16-25$ & 21 & 19 \\
$\mathrm{AP}$ & $29-34$ & 31 & 30 \\
$\mathrm{AM}$ & $51-62$ & 57 & 59 \\
$\mathrm{AL}$ & $41-48$ & 45 & 48 \\
$\mathrm{PL}$ & $50-59$ & 54 & 54 \\
$\mathrm{H}$ & $55-66$ & 61 & 64 \\
$\mathrm{D}_{\min }$ & $36-43$ & 40 & 41 \\
$\mathrm{D}_{\max }$ & $55-67$ & 59 & 64 \\
$\mathrm{~V}_{\min }$ & $25-32$ & 29 & 28 \\
$\mathrm{~V}_{\max }$ & $41-52$ & 46 & 47 \\
pa & $285-330$ & 311 & 307 \\
pm & $239-286$ & 265 & 286 \\
$\mathrm{pp}$ & $308-341$ & 324 & 339 \\
$\mathrm{Ip}$ & $851-946$ & 899 & 932 \\
$\mathrm{DS}$ & $71-74$ & 73 & - \\
$\mathrm{V}$ & $55-56$ & 56 & - \\
$\mathrm{NDV}$ & $126-130$ & 128 & - \\
\hline
\end{tabular}

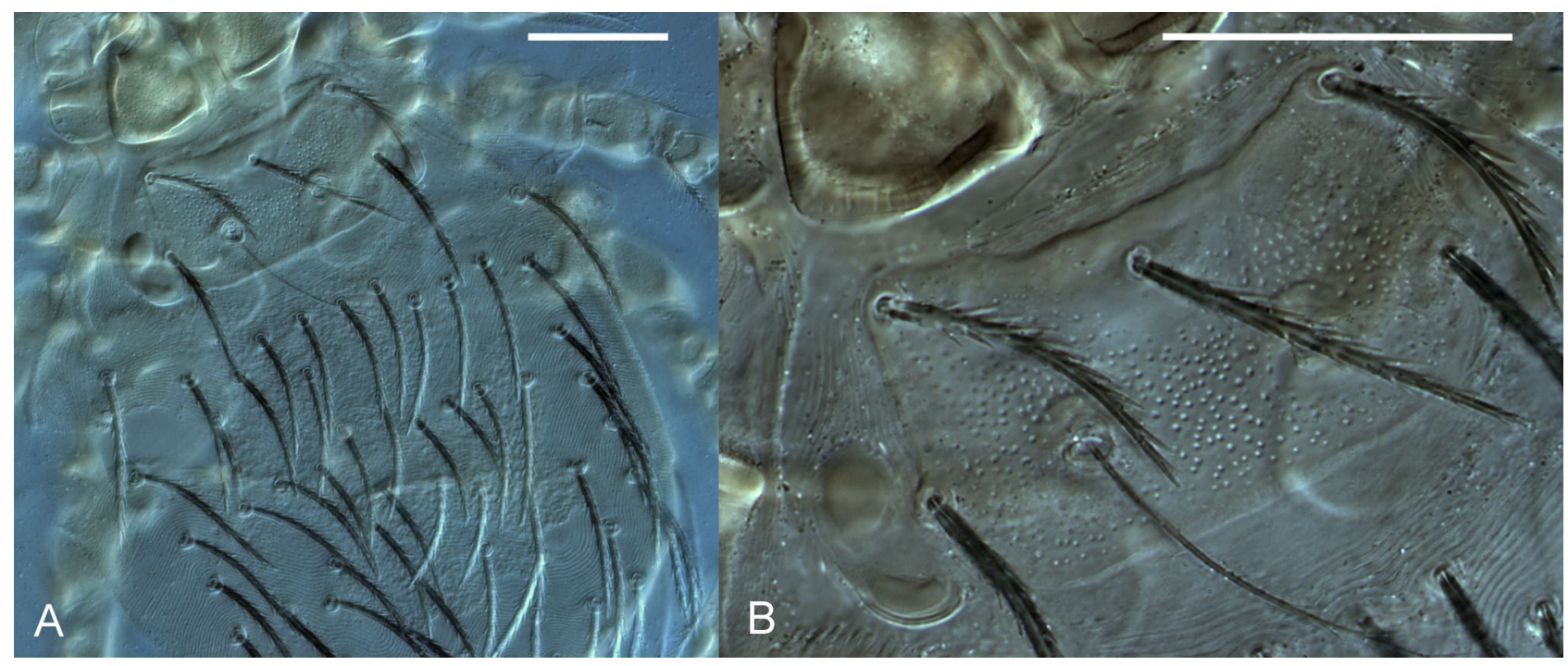

FIGURE 11. Leptotrombidium magnum (Schluger, 1960), lectotype (right sensillum lost). A, dorsal aspect of idiosoma; B, scutum. Scale bars: $50 \mu \mathrm{m}$. 


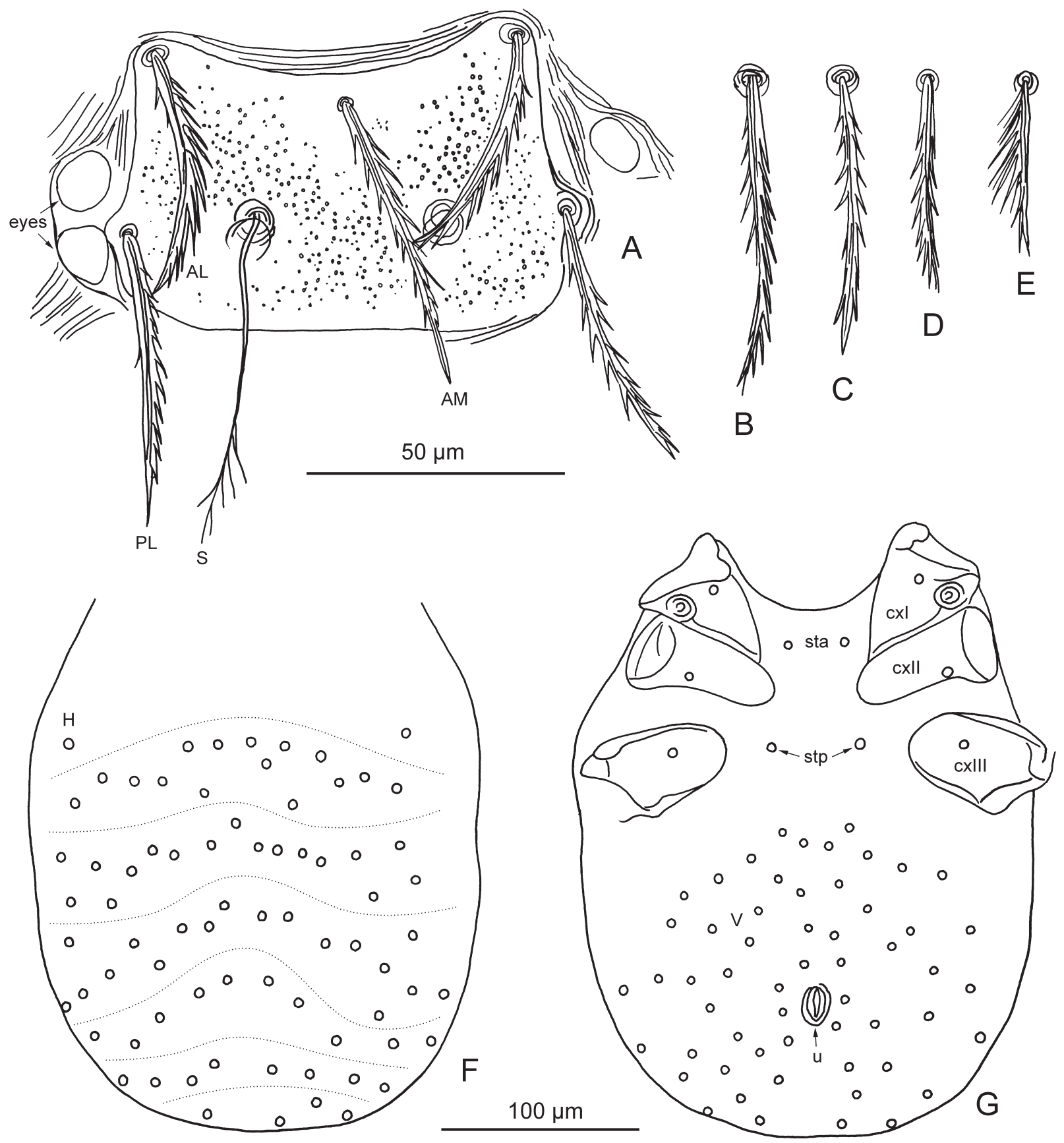

FIGURE 12. Leptotrombidium magnum (Schluger, 1960). A, scutum of paralectotype ZMMU Tdt-3267, specimen 5 (right sensillum lost, posterior right eye not figured); B, humeral seta (C antero-marginal) of paralectotype ZMMU Tdt-3267, specimen 5; C, dorsal idiosomal seta of paralectotype ZMMU Tdt-3267, specimen 5; D, postanal seta of paralectotype ZMMU Tdt3267, specimen 5; E, preanal seta of paralectotype ZMMU Tdt-3267, specimen 5; F, arrangement of dorsal idiosomal setae in paralectotype ZMMU Tdt-3265, specimen 4; G, ventral aspect of idiosoma in paralectotype ZMMU Tdt-3265, specimen 4. Abbreviations as in Fig. 2. Scale bars: $50 \mu \mathrm{m}$ (A-E), $100 \mu \mathrm{m}$ (F, G).

Remarks. This species is a member of the magnum group (Stekolnikov 2013). Its differences from L. globosum are provided above. Leptotrombidium magnum differs from L. keukenschrijveri by a larger scutum (AW 69-79, PW 79-89, and SD 51-58 vs. 59-61, 69-72, and 38-41, respectively) and by longer legs (Ip 851-946 vs. 702-738).

There are no evident differences between L. magnum and $L$. dooleyi, except for a longer AM (66-72 vs. 51-62) and, consequently, $\mathrm{AM}>\mathrm{PL}$ vs. $\mathrm{AM} \geq \mathrm{PL}$ in the latter species that was used for discrimination of these species in the key published by Stekolnikov (2013) (couplet 270). Therefore, we synonymize here L. dooleyi with L. magnum . 

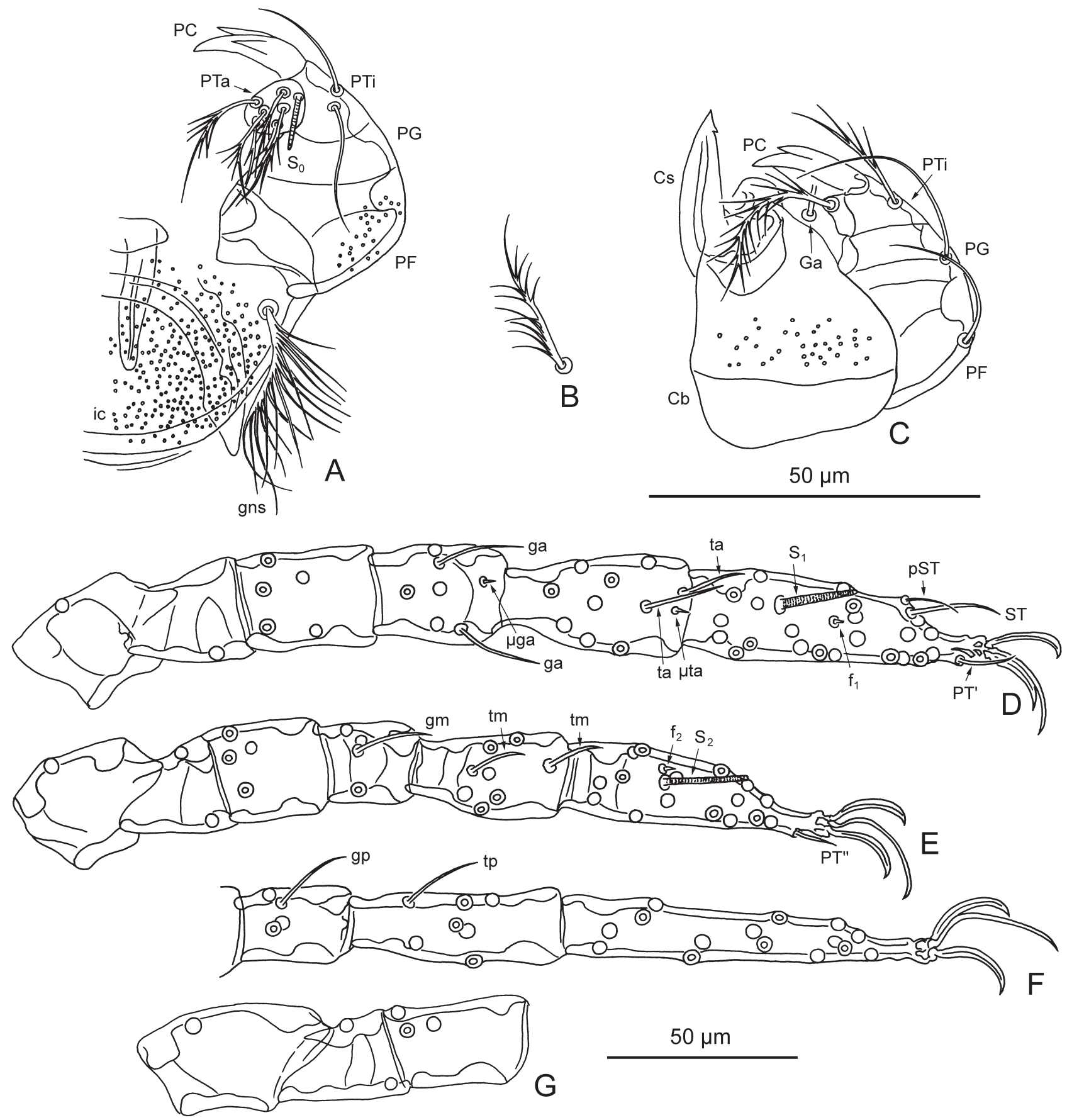

FIGURE 13. Leptotrombidium magnum (Schluger, 1960), paralectotype ZMMU Tdt-3266, specimen 2. A, dorsal aspect of gnathosoma; B, galeal (deutorostral) seta; C, ventral aspect of gnathosoma (galeal seta broken); D, leg I (trochanter-tarsus); E, leg II (trochanter-tarsus); F, leg III (genu-tarsus); G, leg III (trochanter-telofemur). Abbreviations as in Fig. 2. Scale bars: 50 $\mu \mathrm{m}(\mathrm{A}-\mathrm{C}), 50 \mu \mathrm{m}(\mathrm{D}-\mathrm{G})$.

Leptotrombidium submagnum is also definitely identical to L. magnum. The characters of the former species given by its authors to discriminate it from $L$. magnum and $L$. dooleyi were as follows: $\mathrm{PL}>\mathrm{AM}>\mathrm{AL}, \mathrm{PW} / \mathrm{AP}=2.5$, and 16-17 setae in $1^{\text {st }}$ posthumeral row (Wang et al. 1988). According to our data, $\mathrm{PW} / \mathrm{AP}=2.47-2.89$ (mean 2.69) in the type series of L. magnum. The number of setae in $1^{\text {st }}$ posthumeral row was 14 and 15 in the two paralectotypes with $\mathrm{fD}$ recorded. Taking into account a high level of variation in the arrangement of idiosomal setae in all chigger species with large DS, the difference between 14-15 and 16-17 cannot be estimated as taxonomically significant. The difference in the length of PL (50-59 in L. magnum and 62-66 in L. submagnum) that resulted in AM $\geq$ PL vs. $\mathrm{PL}>\mathrm{AM}$ is also not weighty. In addition, we can note that NDV is 118-125 in L. submagnum and 126-130 in $L$. 
magnum. This slight difference does not constitute a basis for species discrimination. Therefore, we synonymize here L. submagnum with L. magnum.

\section{Leptotrombidium monstrosum (Schluger, 1960)}

(Figs. 14-16)

Trombicula (Leptotrombidium) monstrosa Schluger, 1960 (in Schluger et al. 1960b): 1798, fig. 6.

Leptotrombidium (Leptotrombidium) monstrosa: Traub \& Lakshana 1966: 282.

Leptotrombidium (Leptotrombidium) monstrosum: Lakshana 1973: 8; Vercammen-Grandjean \& Langston 1976: 569, pl. 155;

Kudryashova 2004: 27; Chau et al. 2007: 54, fig. 23.

Leptotrombidium monstrosum: Stekolnikov 2013: 47; 2021: 123.

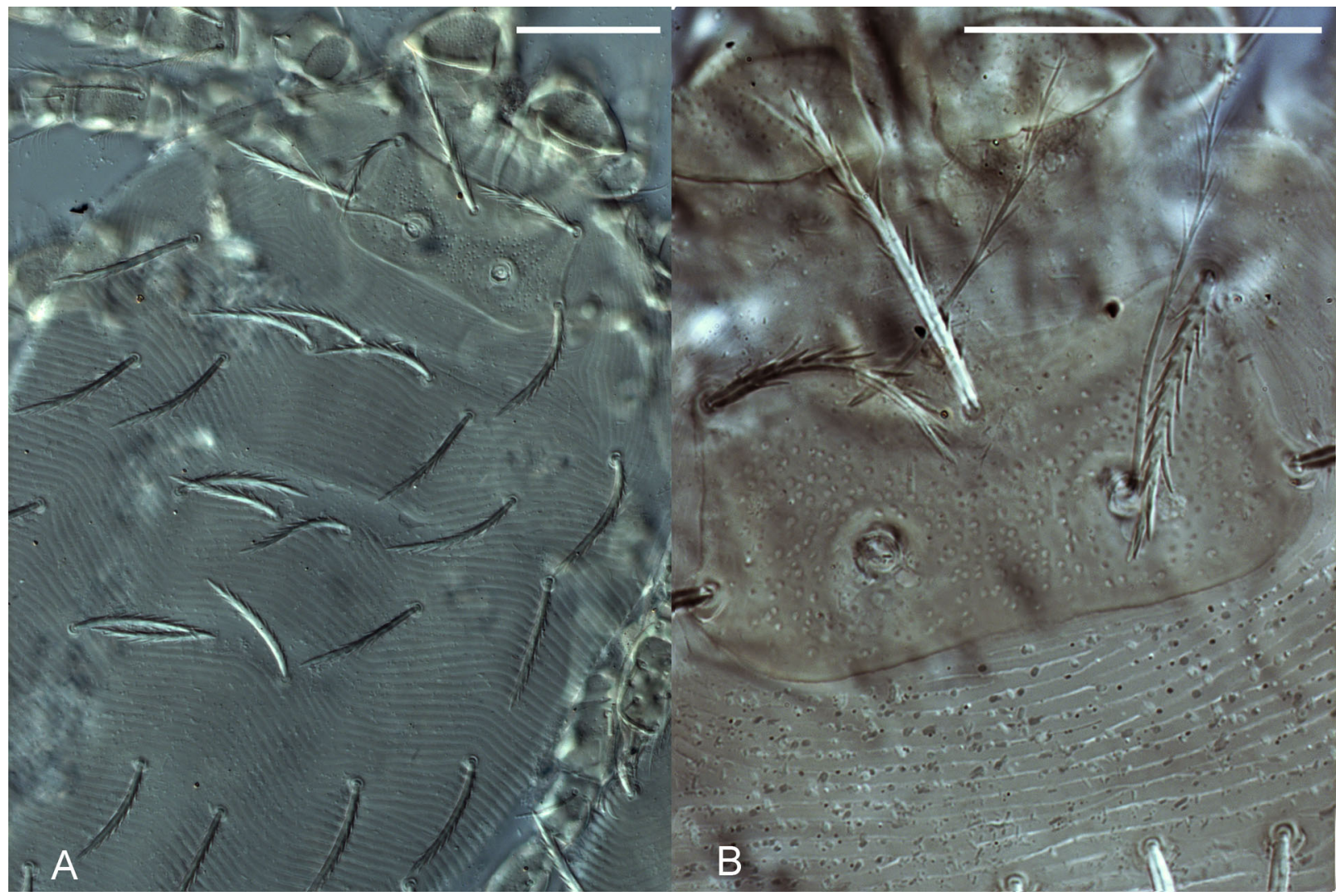

FIGURE 14. Leptotrombidium monstrosum (Schluger, 1960). A, dorsal aspect of idiosoma of lectotype (right sensillum lost); B, scutum of paralectotype ZMMU Tdt-3250, specimen 2 (left sensillum detached). Scale bars: $50 \mu \mathrm{m}$.

Diagnosis. $\mathrm{SIF}=7 \mathrm{~B}-\mathrm{B}-3-2111.0000 ; \mathrm{fsp}=7.7 .7 ; \mathrm{fCx}=1.1 .1 ; \mathrm{fSt}=2.2 ; \mathrm{fPp}=\mathrm{N} / \mathrm{N} / \mathrm{BNB} ; \mathrm{fSc}: \mathrm{AM} \geq \mathrm{PL}>\mathrm{AL} ; \mathrm{Ip}$ $=708-784 ; \mathrm{fD}=2 \mathrm{H}-8-6-6-4-2-2 ; \mathrm{DS}=30 ; \mathrm{V}=30-33 ; \mathrm{NDV}=60-63$. Standard measurements of type series given in Table 6.

Description (larva) (based on lectotype and 21 paralectotypes, fD recorded in three specimens). IDIOSOMA (Figs. 14A, 15B-G). Eyes $2+2 ; 30$ barbed dorsal idiosomal setae, including one pair of humeral setae, arranged 2H-8-6-6-4-2-2; 4 sternal setae; 30-33 ventral setae; NDV $=60-63$.

GNATHOSOMA (Fig. 16A-E). Cheliceral blade with tricuspid cap; gnathobase covered with puncta and bears 1 pair of branched gnathocoxal (tritorostral) setae; cheliceral base covered with puncta, palpal femur with few puncta; galeal (deutorostral) seta branched; palpal claw with 3 prongs; setae on palpal femur and genu nude, dorsal palpal tibial seta branched, lateral palpal tibial seta nude; ventral palpal tibial seta branched; palpal tarsus with 7 branched setae and tarsala $(\omega)$.

SCUTUM (Figs. 14, 15A). Rectangular, moderately covered with rather large puncta, projected posterior to PL, posterior margin slightly concave in middle part; AM posterior to level of AL, sensillary (trichobothrial) bases at level of PL or slightly anterior (P-PL $-\mathrm{PSB}=-4-1 \mu \mathrm{m}$ ); all scutal setae barbed similarly to dorsal idiosomal setae; $\mathrm{AM} \geq \mathrm{PL}>\mathrm{AL}$; flagelliform sensilla (trichobothria) with about 8 branches in distal part. 


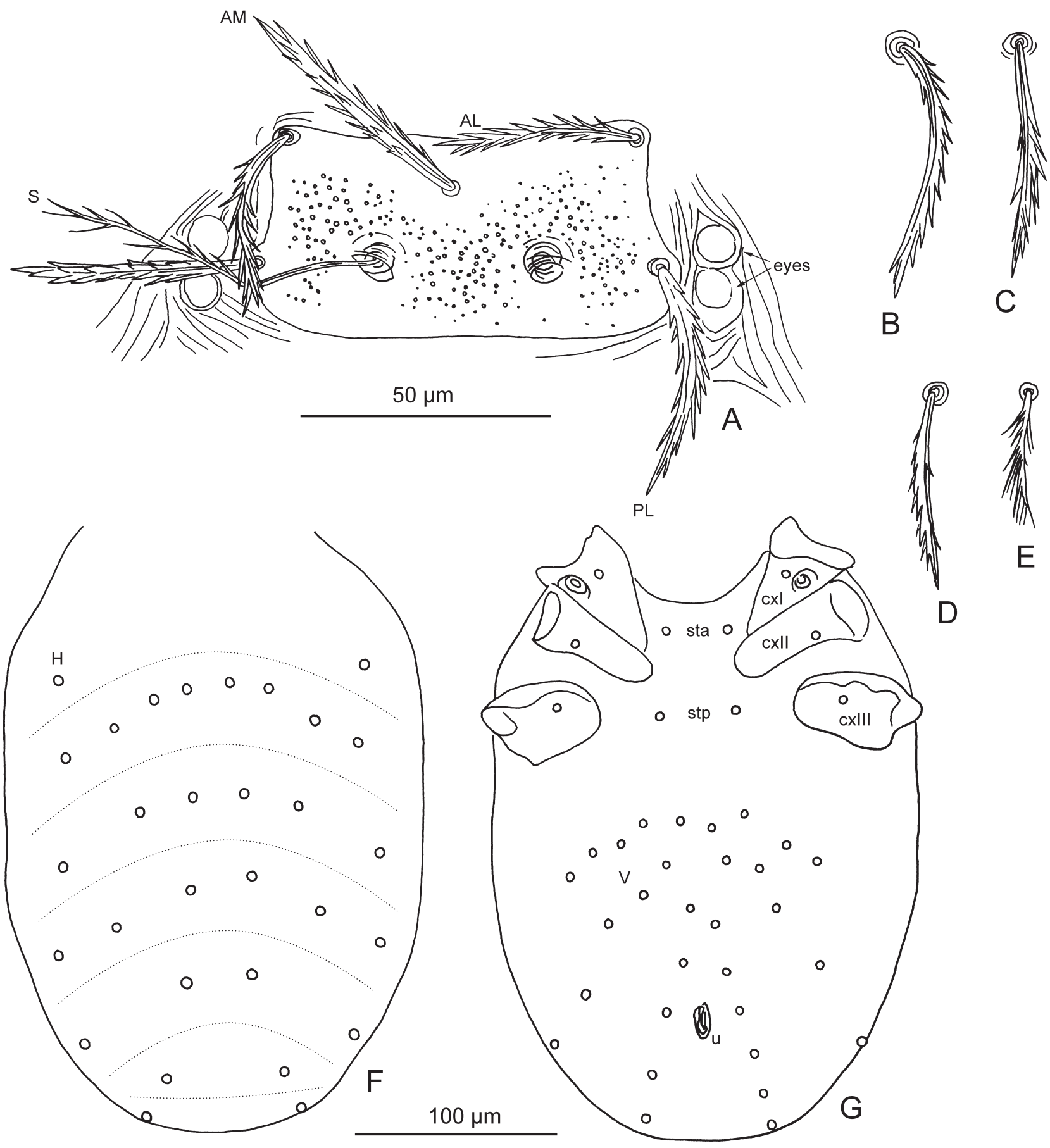

FIGURE 15. Leptotrombidium monstrosum (Schluger, 1960). A, scutum of lectotype (right sensillum lost); B, humeral seta (C antero-marginal) of lectotype; $\mathbf{C}$, dorsal idiosomal seta of lectotype; D, postanal seta of lectotype; $\mathbf{E}$, preanal seta of lectotype; $\mathbf{F}$, arrangement of dorsal idiosomal setae in paralectotype ZMMU Tdt-3244, specimen 1; G, ventral aspect of idiosoma in paralectotype ZMMU Tdt-3244, specimen 1. Abbreviations as in Fig. 2. Scale bars: $50 \mu \mathrm{m}(\mathrm{A}-\mathrm{E}), 100 \mu \mathrm{m}(\mathrm{F}, \mathrm{G})$.

LEGS (Fig. 16F-H). All 7-segmented, with 1 pair of claws and claw-like empodium. Leg I: coxa with 1 branched seta (1B); trochanter 1B; basifemur 1B; telofemur 5B; genu 4B, 2 genualae $(\sigma)$, microgenuala $(\kappa)$; tibia 8B, 2 tibialae $(\varphi)$, microtibiala $(\kappa)$; tarsus $22 \mathrm{~B}$, tarsala $(\omega)$, microtarsala $(\varepsilon)$ distal to tarsala, subterminala $(\zeta)$, parasubterminala $(z)$,

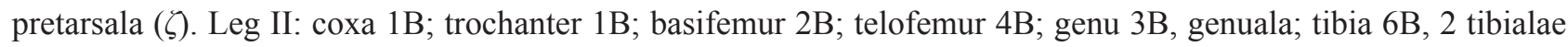
$(\varphi)$; tarsus $16 \mathrm{~B}$, tarsala $(\omega)$, microtarsala $(\varepsilon)$ posterior to tarsala, pretarsala $(\zeta)$. Leg III: coxa $1 \mathrm{~B}$; trochanter $1 \mathrm{~B}$; basifemur 2B; telofemur 3B; genu 3B, genuala; tibia 6B, tibiala; tarsus 15B.

Distribution and hosts. This species was described from North Vietnam, Quang Ninh Province, ex Leopoldamys 
sabanus (= Rattus sabanus) and Tupaia belangeri chinensis $[=$ T. glis modesta $;=$ T. hongaiensis (nomen nudum)] (Schluger et al. 1960b). Later on, it was recorded in Thailand (Lakshana 1973) from Menetes berdmorei. Vercammen-Grandjean \& Langston (1976) added also Leopoldamys edwardsi (Thomas) [= R. grochovskiae (nomen nudum)] to the list of hosts based on examination of syntypes. Chau et al. (2007) also reported this species from Atherurus macrourus (L.), Callosciurus erythraeus (Pallas), Dremomys rufigenis, Rattus andamanensis (Blyth) (= R. koratensis), Tamiops rodolphii (Milne-Edwards), Hylomys suillus, Paradoxurus hermaphroditus, and birds Gallus gallus domesticus (L.) and Francolinus pintadeanus (Scopoli), probably, from Vietnam.

TABLE 6. Morphometric (AW-Ip, $\mu \mathrm{m}$ ) and meristic (DS-NDV) traits of Leptotrombidium monstrosum (Schluger, 1960) $(\mathrm{n}=22)$.

\begin{tabular}{|c|c|c|c|}
\hline & Range & Mean & Lectotype \\
\hline AW & $67-73$ & 69 & 68 \\
\hline PW & $78-89$ & 83 & 79 \\
\hline SB & $33-40$ & 36 & 34 \\
\hline ASB & $25-31$ & 29 & 25 \\
\hline PSB & $15-21$ & 18 & 15 \\
\hline SD & $39-51$ & 46 & 39 \\
\hline P-PL & $14-20$ & 17 & 14 \\
\hline AP & $26-30$ & 27 & 26 \\
\hline $\mathrm{AM}$ & $44-57$ & 53 & 51 \\
\hline $\mathrm{AL}$ & $28-45$ & 39 & 38 \\
\hline PL & $44-55$ & 49 & 50 \\
\hline $\mathrm{H}$ & $52-60$ & 55 & 57 \\
\hline $\mathrm{D}_{\min }$ & $34-40$ & 38 & 40 \\
\hline $\mathrm{D}_{\max }$ & $50-60$ & 53 & 52 \\
\hline $\mathrm{V}_{\min }$ & $22-28$ & 25 & 26 \\
\hline $\mathrm{V}_{\max }$ & $39-48$ & 43 & 39 \\
\hline pa & $246-276$ & 259 & 261 \\
\hline $\mathrm{pm}$ & $205-236$ & 224 & 222 \\
\hline $\mathrm{pp}$ & $252-282$ & 270 & 270 \\
\hline Ip & $708-784$ & 752 & 753 \\
\hline DS & $30-30$ & 30 & - \\
\hline $\mathrm{V}$ & $30-33$ & 31 & - \\
\hline NDV & $60-63$ & 61 & - \\
\hline
\end{tabular}

Type material examined. Lectotype larva (ZMMU Tdt-3250, specimen 1, designated here) ex L. edwardsi [labeled as Rattus sp. and R. grochovskii (nomen nudum)] No 45, VIETNAM: Quang Ninh Province, Ha Lam District, Ha Long (= Hon Gai), 6 February 1956, coll. I.M. Grochovskaja. Twelve paralectotypes larvae (ZMMU Tdt-3244, specimens 1-5; ZMMU Tdt-3245, specimens 1, 2, 4, 6; ZMMU Tdt-3246, specimens 1, 4, 5) ex Tupaia belangeri chinensis [labeled as T. glis and T. hongaiensis (nomen nudum)] No 42, 3 February 1956, other data same as for lectotype; one paralectotype larva (ZMMU Tdt-3248, specimen 4) ex L. edwardsi [labeled as Rattus sp. and R. grochovskii (nomen nudum)] No 40, 3 February 1956, other data same as for lectotype; one paralectotype larva (ZMMU Tdt-3249, specimen 1) ex L. edwardsi [labeled as Rattus sp. and R. grochovskii (nomen nudum)] No 44, other data same as for lectotype; five paralectotypes larvae (ZMMU Tdt-3250, specimens 2, 3, 5, 6, 7) with same data as lectotype; two paralectotypes larvae (ZMMU Tdt-3268, specimens 1,2) ex Tupaia belangeri (labeled as $T$. glis and T. ferruginea) No 29, 1 February 1956, other data same. 

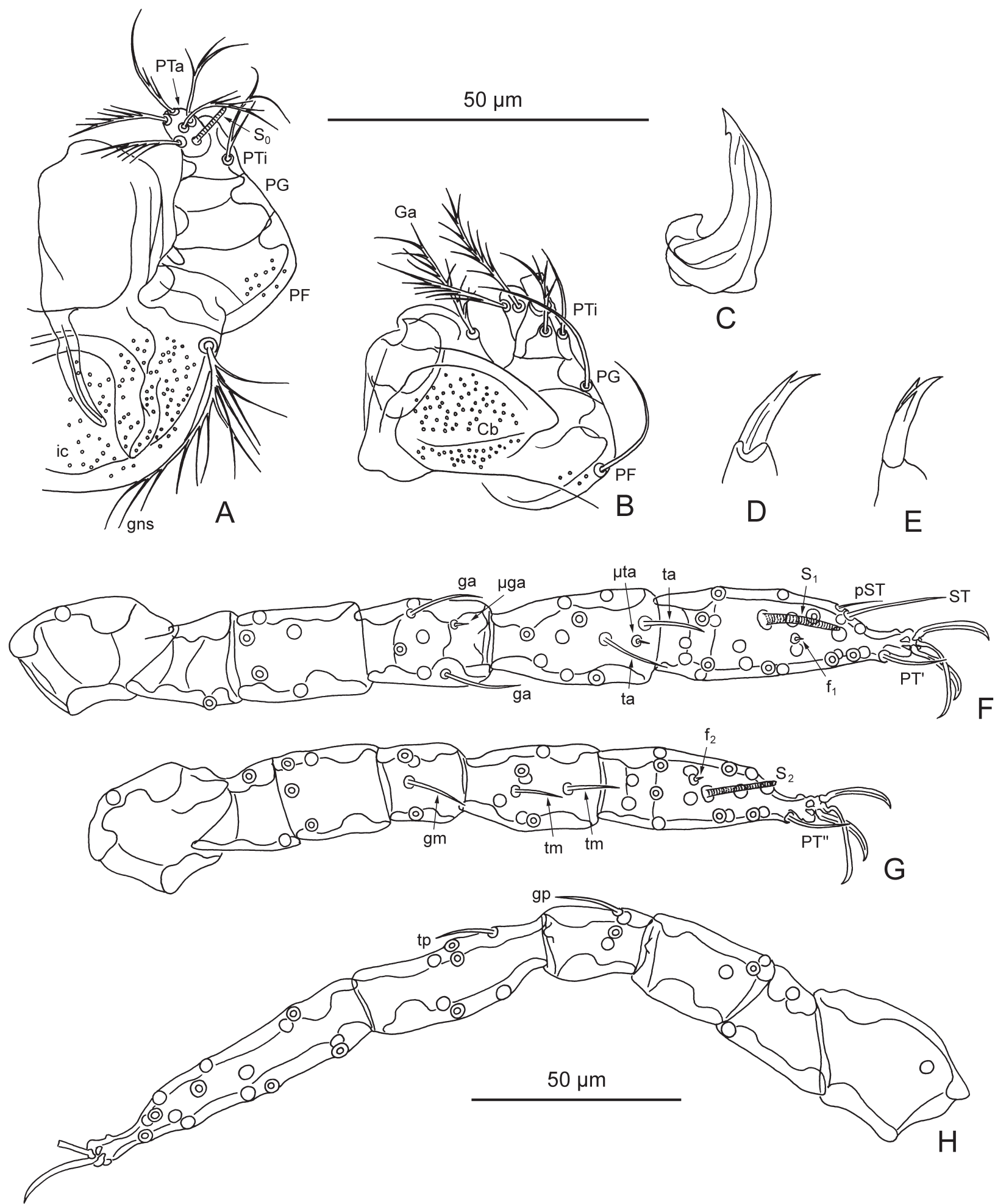

FIGURE 16. Leptotrombidium monstrosum (Schluger, 1960). A, ventral aspect of gnathosoma of lectotype (cheliceral blade lost); B, dorsal aspect of gnathosoma of lectotype (palpal claw broken); C, cheliceral blade; D, palpal claw; E, palpal claw (other side); F, leg I (trochanter-tarsus) of paralectotype ZMMU Tdt-3250, specimen 2; G, leg II (trochanter-tarsus) of paralectotype ZMMU Tdt-3250, specimen 2; H, leg III (trochanter-tarsus) of paralectotype ZMMU Tdt-3250, specimen 2 (one claw and empodium lost). Abbreviations as in Fig. 2. Scale bars: $50 \mu \mathrm{m}(\mathrm{A}-\mathrm{E}), 50 \mu \mathrm{m}(\mathrm{F}-\mathrm{H})$.

Remarks. This species is a member of the scanloni group (Stekolnikov 2013), which includes three species. Leptotrombidium monstrosum differs from L. scanloni Traub and Lakshana, 1966 in having the ventral palpal tibial 
seta branched $(\mathrm{fPp}=\mathrm{N} / \mathrm{N} / \mathrm{BNB}$ vs. N/N/BNN); sensillary bases situated at the level of PL or slightly anterior to them vs. posterior; and larger scutum (AW 67-73, PW 78-89, and AP 26-30 vs. 62-66, 73-78, and 23-25, respectively). Leptotrombidium monstrosum differs from L. hanseni Traub and Lakshana, 1966 in having a slightly lesser number of idiosomal setae (DS 30, V 30-33, and NDV 60-63 vs. 34, 34, and 68, respectively); fD = 2H-8-6-6-4-2-2 vs. $2 \mathrm{H}-8-6-6-6-4-2$; and shorter legs (Ip 708-784 vs. 847). Taxonomical significance of these rather slight differences is unclear, since no data on the variation of NDV and Ip are available for $L$. hanseni. Probably, the latter species should be synonymized with $L$. monstrosum, but this suggestion needs a verification based on a larger material.

Traub \& Lakshana (1966) stated that L. hanseni differs from L. monstrosum, in addition to the difference by $\mathrm{fD}$, also by a smaller scutum (PW 84, SB 36, and AP 25 vs. 100, 45, and 33, respectively), but our measurements of L. monstrosum do not support that observation (Table 6). The source of the values provided by Traub \& Lakshana as measurements of $L$. monstrosum is unclear. These data do not coincide with those in the original description (Schluger et al. 1960b), and these authors did not mention the examination of any material on L. monstrosum.

\section{Genus Lorillatum Nadchatram, 1963}

\section{Lorillatum attapinum (Schluger, Grochovskaja, Ngu, Hoe and Tung, 1963)}

(Figs. 17-19)

Trombicula attapina Schluger, Grochovskaja, Ngu, Hoe and Tung, 1963: 692, figs. 8-15.

Lorillatum attapinum: Vercammen-Grandjean \& Langston 1976: 947; Kudryashova 2004: 14; Stekolnikov 2021 : 131.

Lorillatum attapina: Chau et al. 2007: 71, figs. 33, 34.

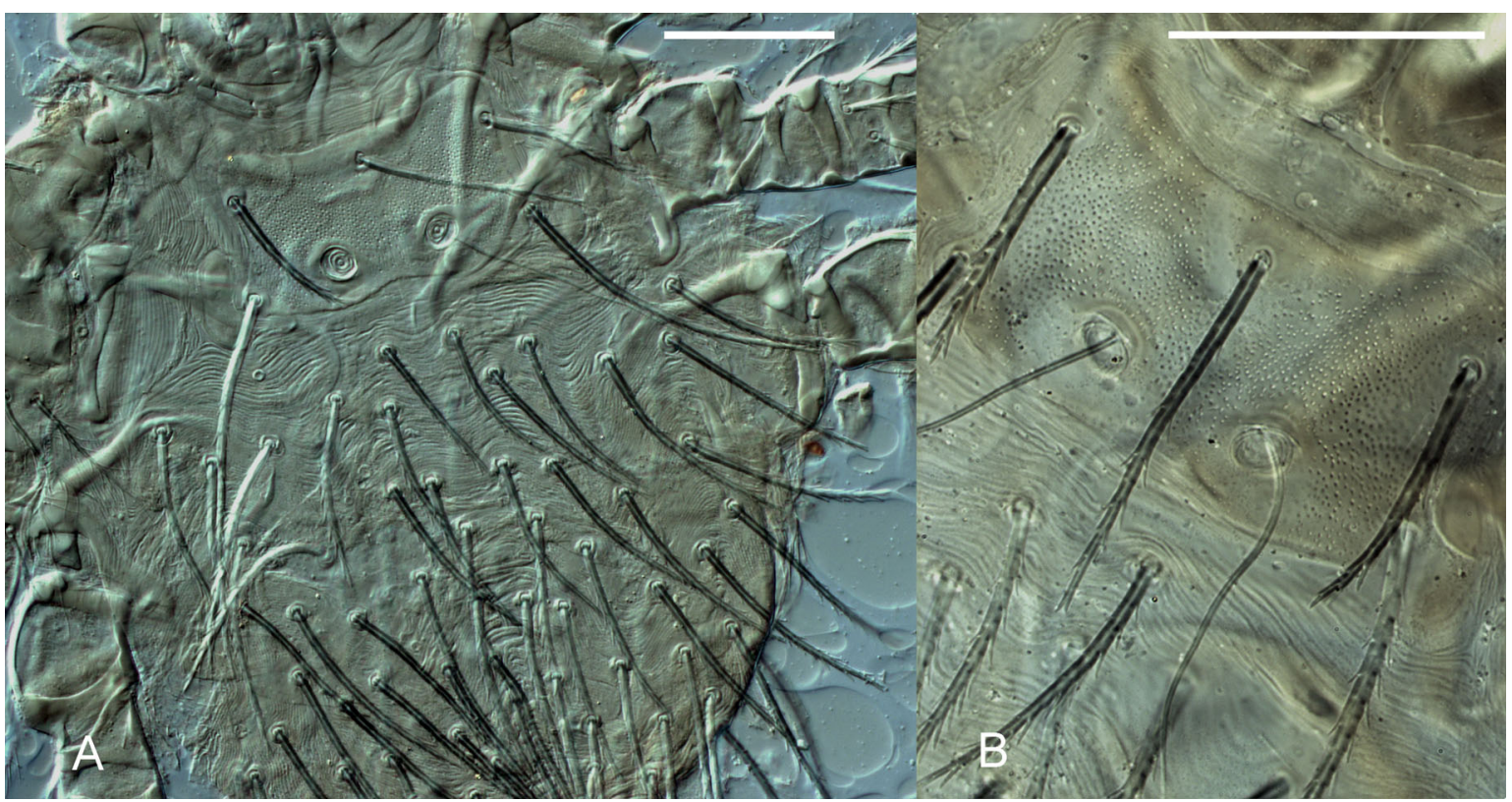

FIGURE 17. Lorillatum attapinum (Schluger, Grochovskaja, Ngu, Hoe and Tung, 1963). A, dorsal aspect of idiosoma in paralectotype ZMMU Tdt-3140, specimen 1 (left sensillum lost); B, scutum of lectotype. Scale bars: $50 \mu \mathrm{m}$.

Diagnosis. $\mathrm{SIF}=7 \mathrm{~B}-\mathrm{B}-3-2111.0201 ; \mathrm{fsp}=7.7 .7 ; \mathrm{fCx}=1.1 .1 ; \mathrm{fSt}=2.2 ; \mathrm{fPp}=\mathrm{B} / \mathrm{N} / \mathrm{NNb} ; \mathrm{fSc}: \mathrm{PL}>\mathrm{AM}>\mathrm{AL} ; \mathrm{Ip}=$ 924-1056; fD = 2H-[8-(1-3)]-10-10+18; DS = 51-56; V = 34-40; NDV = 87-91. Standard measurements of type series given in Table 7 .

Description (larva) (based on lectotype and 4 paralectotypes, fD recorded in one specimen). IDIOSOMA (Figs. $17 \mathrm{~A}, 18 \mathrm{~B}-\mathrm{G})$. Eyes $2+2 ; 51-56$ barbed dorsal idiosomal setae, including one pair of humeral setae, $1^{\text {st }}$ posthumeral row (C except humeral setae) double, with 8 anterior and 3 posterior setae, $2^{\text {nd }}$ row (D) and $3^{\text {rd }}$ row (E) with 10 setae each plus 18 setae with unclear distribution by rows; 4 sternal setae; 34-40 ventral setae; NDV = 87-91. 


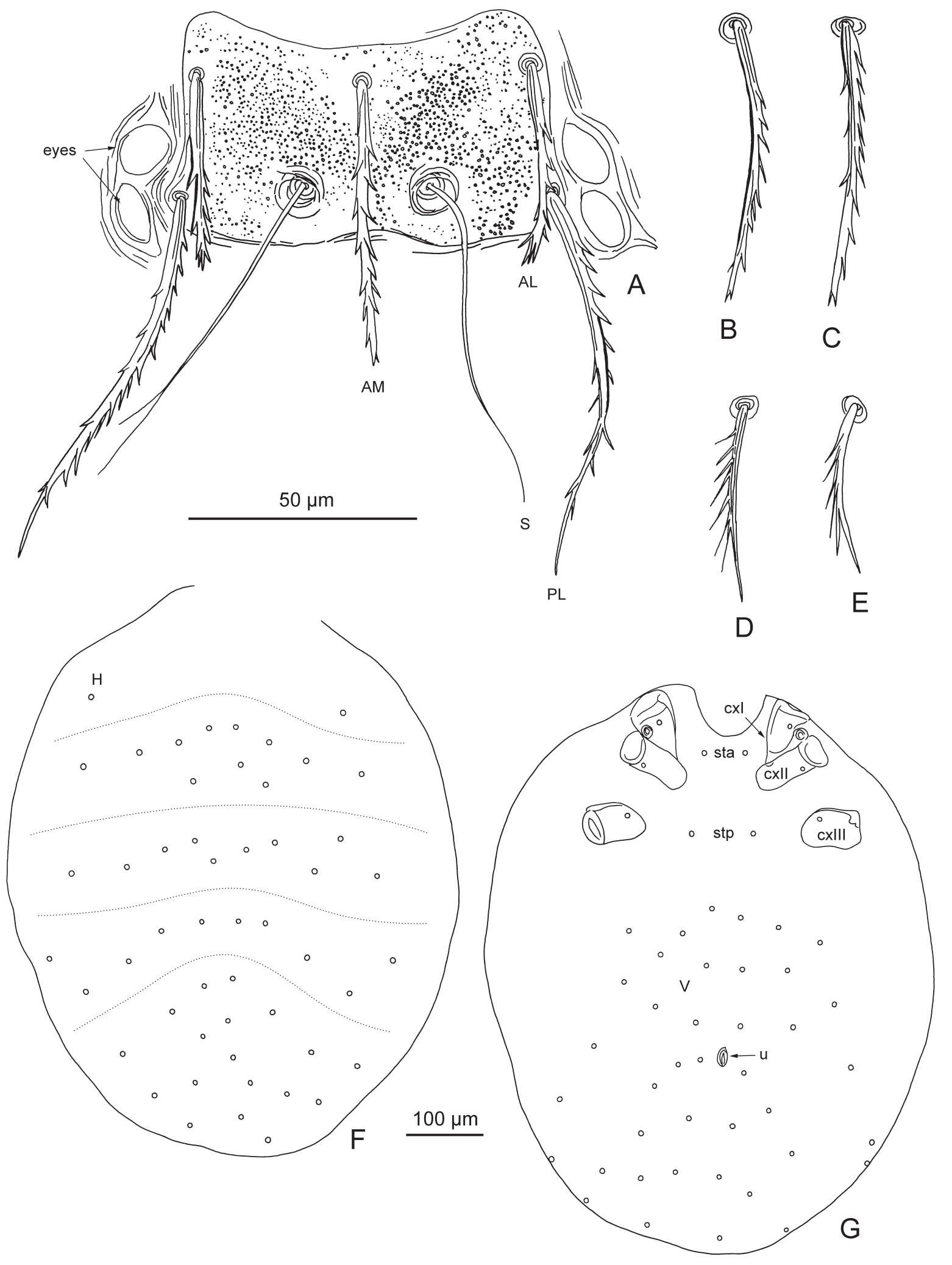

FIGURE 18. Lorillatum attapinum (Schluger, Grochovskaja, Ngu, Hoe and Tung, 1963). A, scutum of paralectotype ZMMU Tdt-3141, specimen 1; B, humeral seta (C antero-marginal) of paralectotype ZMMU Tdt-3141, specimen 1; C, dorsal idiosomal seta of paralectotype ZMMU Tdt-3141, specimen 1; D, postanal seta of paralectotype ZMMU Tdt-3141, specimen 1; E, preanal seta of paralectotype ZMMU Tdt-3141, specimen 1; F, arrangement of dorsal idiosomal setae in paralectotype ZMMU Tdt3142, specimen 1; G, ventral aspect of idiosoma in paralectotype ZMMU Tdt-3142, specimen 1. Abbreviations as in Fig. 2. Scale bars: $50 \mu \mathrm{m}$ (A-E), $100 \mu \mathrm{m}$ (F, G). 

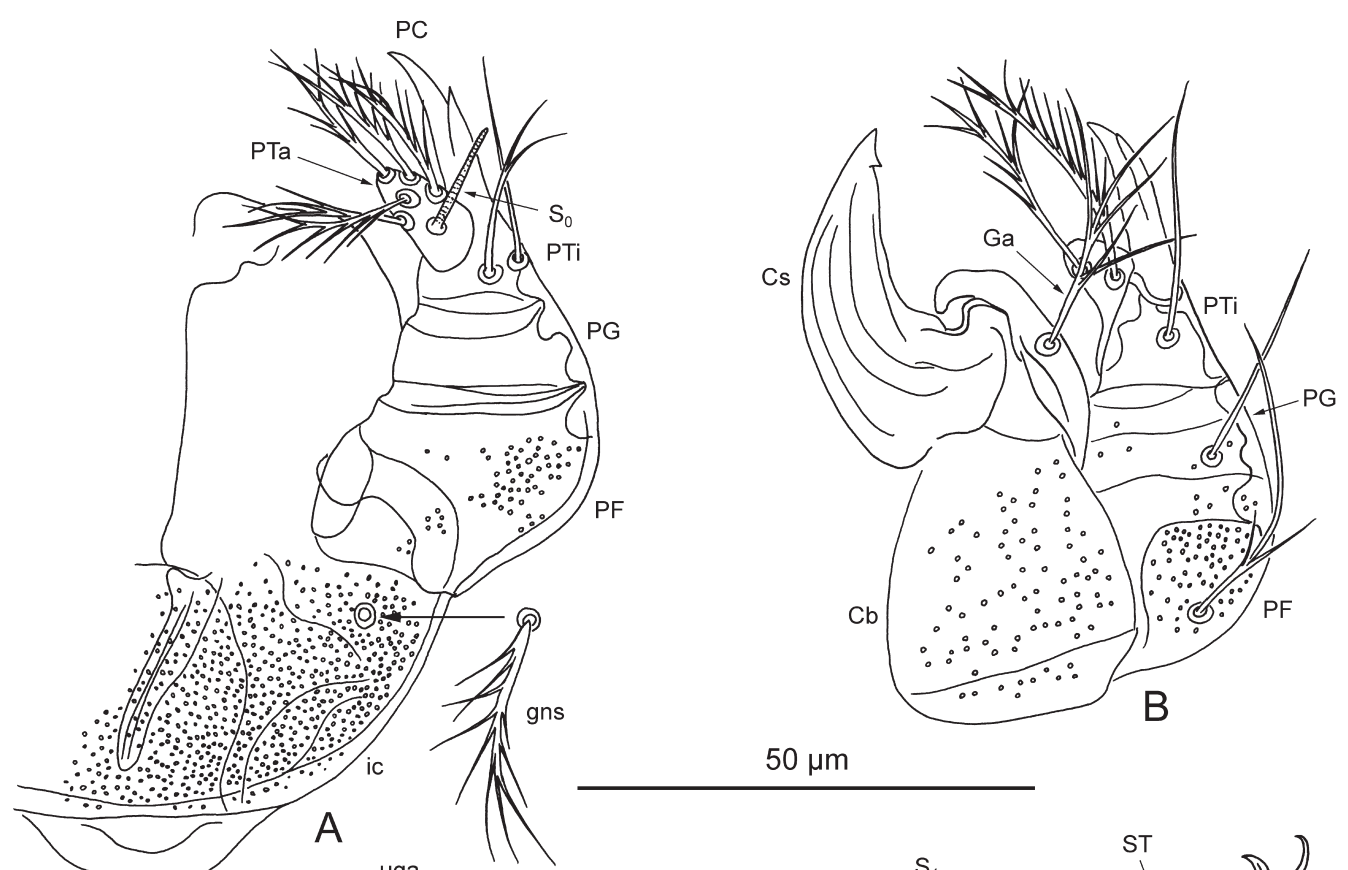

$50 \mu \mathrm{m}$
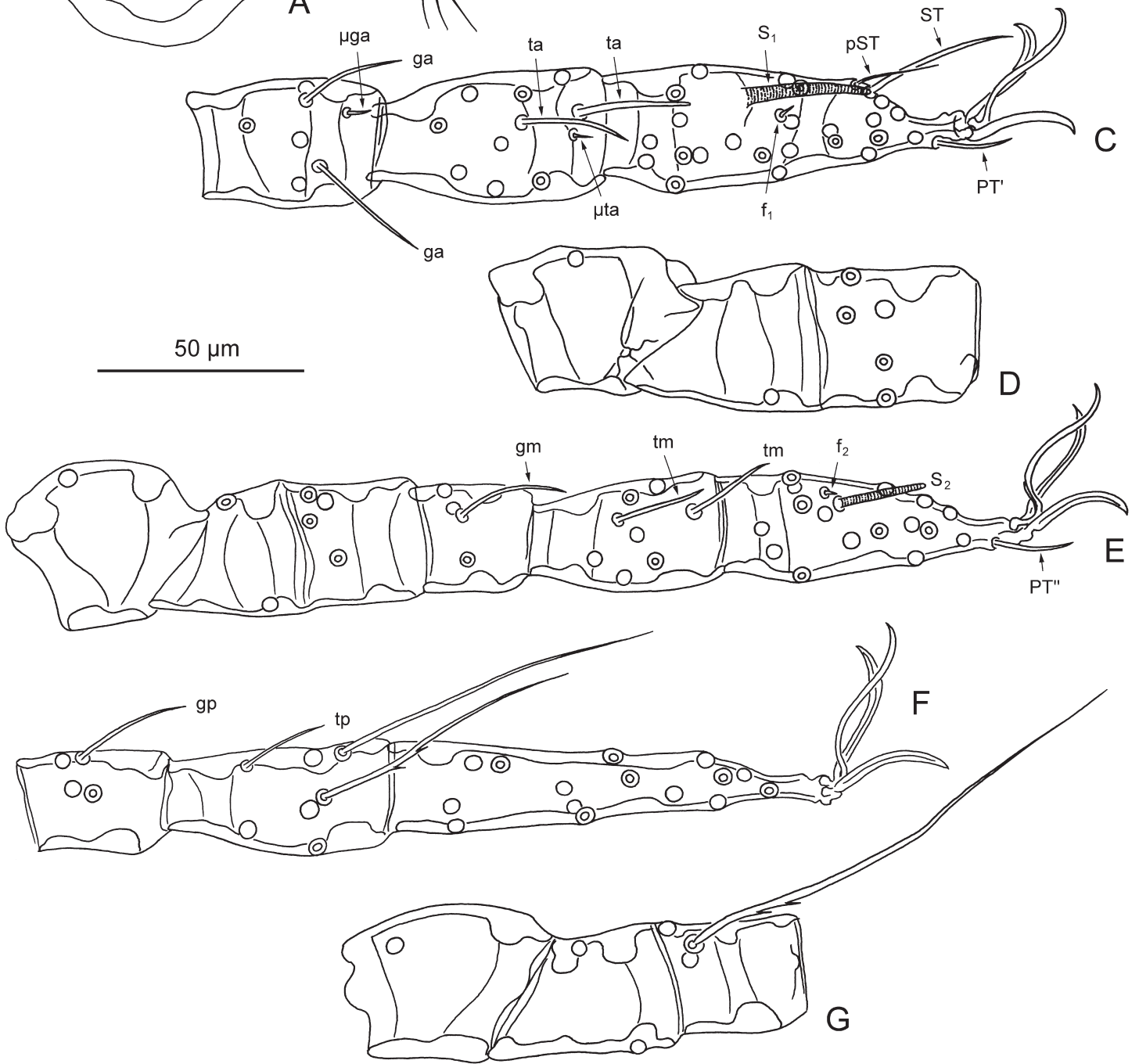

FIGURE 19. Lorillatum attapinum (Schluger, Grochovskaja, Ngu, Hoe and Tung, 1963), lectotype. A, ventral aspect of gnathosoma (gnathocoxal seta detached); B, dorsal aspect of gnathosoma; C, leg I (genu-tarsus); D, leg I (trochanter-telofemur); E, leg II (trochanter-tarsus); F, leg III (genu-tarsus); G, leg III (trochanter-telofemur). Abbreviations as in Fig. 2. Scale bars: $50 \mu \mathrm{m}(\mathrm{A}, \mathrm{B}), 50 \mu \mathrm{m}(\mathrm{C}-\mathrm{G})$. 
TABLE 7. Morphometric (AW-Ip, $\mu \mathrm{m}$ ) and meristic (DS-NDV) traits of Lorillatum attapinum (Schluger, Grochovskaja, Ngu, Hoe and Tung, 1963) ( $\mathrm{n}=5)$.

\begin{tabular}{llll}
\hline & Range & Mean & Lectotype \\
\hline $\mathrm{AW}$ & $72-81$ & 76 & 77 \\
$\mathrm{PW}$ & $82-92$ & 86 & 85 \\
$\mathrm{SB}$ & $30-36$ & 32 & 30 \\
$\mathrm{ASB}$ & $38-43$ & 40 & 41 \\
$\mathrm{PSB}$ & $13-16$ & 14 & 16 \\
$\mathrm{SD}$ & $51-56$ & 54 & 57 \\
$\mathrm{P}-\mathrm{PL}$ & $10-13$ & 12 & 13 \\
$\mathrm{AP}$ & $26-30$ & 28 & 30 \\
$\mathrm{AM}$ & $63-66$ & 64 & 66 \\
$\mathrm{AL}$ & $44-46$ & 45 & 45 \\
$\mathrm{PL}$ & $85-97$ & 91 & 97 \\
$\mathrm{H}$ & $60-69$ & 64 & 61 \\
$\mathrm{D}_{\min }$ & $51-55$ & 53 & 55 \\
$\mathrm{D}_{\max }$ & $64-75$ & 70 & 72 \\
$\mathrm{~V}_{\min }$ & $37-44$ & 41 & 43 \\
$\mathrm{~V}_{\max }$ & $56-64$ & 59 & 61 \\
pa & $331-372$ & 356 & 372 \\
$\mathrm{pm}$ & $270-312$ & 296 & 311 \\
$\mathrm{pp}$ & $323-373$ & 351 & 373 \\
$\mathrm{Ip}$ & $924-1056$ & 1003 & 1056 \\
$\mathrm{DS}$ & $51-56$ & 53 & 56 \\
$\mathrm{~V}$ & $34-40$ & 37 & 34 \\
$\mathrm{NDV}$ & $87-91$ & 90 & 90 \\
\hline
\end{tabular}

GNATHOSOMA (Fig. 19A, B). Cheliceral blade with tricuspid cap; gnathobase densely covered with small puncta and bears 1 pair of branched gnathocoxal (tritorostral) setae; cheliceral base and palpal femur sparsely covered with puncta, palpal genu with few puncta; galeal (deutorostral) seta branched; palpal claw with 3 prongs; seta on palpal femur with few branches, seta on palpal genu nude, dorsal and lateral palpal tibial setae nude, ventral palpal tibial seta with one branch; palpal tarsus with 7 branched setae and tarsala $(\omega)$.

SCUTUM (Figs. 17, 18A). Rectangular, densely covered with small puncta, with prominent anterolateral shoulders anterior to AL, anterior scutal margin concave, posterior margin bilobate; $\mathrm{AM}$ at level of AL, sensillary (trichobothrial) bases slightly anterior to level of PL (PSB - P-PL $=1-3 \mu \mathrm{m}$ ); all scutal setae barbed similarly to dorsal idiosomal setae; PL very long, pointed; PL $>$ AM $>$ AL; flagelliform sensilla (trichobothria) with one branch or nude.

LEGS (Fig. 19C-J). All 7-segmented, with 1 pair of claws and claw-like empodium. Leg I: coxa with 1 branched seta (1B); trochanter 1B; basifemur 1B; telofemur 5B; genu 4B, 2 genualae $(\sigma)$, microgenuala $(\kappa)$; tibia 8B, 2 tibialae $(\varphi)$, microtibiala $(\kappa)$; tarsus $23 \mathrm{~B}$, tarsala $(\omega)$, microtarsala $(\varepsilon)$ distal to tarsala, subterminala $(\zeta)$, parasubterminala $(z)$, pretarsala $(\zeta)$. Leg II: coxa 1B; trochanter 1B; basifemur 2B; telofemur 4B; genu 3B, genuala; tibia 6B, 2 tibialae $(\varphi)$; tarsus 16B, tarsala $(\omega)$ II shorter and slender than tarsala I, microtarsala $(\varepsilon)$ posterior to tarsala, pretarsala $(\zeta)$. Leg III: coxa 1B; trochanter 1B; basifemur $2 \mathrm{~B}$; telofemur $2 \mathrm{~B}$ and one very long flagelliform seta with few cilia in basal part; genu 3B, genuala; tibia 4B and two long flagelliform setae, nude or with few cilia, tibiala; tarsus 15B.

Distribution and hosts. This species was described from North Vietnam, Ha Giang Province, ex Crocidura sp. [= Crocidura leucrura (nomen nudum? lapsus calami?)] (Schluger et al. 1963).

Type material examined. Lectotype larva (ZMMU Tdt-3141, specimen 4, designated here) ex Crocidura sp. No 218, VIETNAM: Ha Giang Province, Ha Giang, 25 May 1956, coll. I.M. Grochovskaja. Three paralectotypes larvae (ZMMU Tdt-3141, specimen 5; ZMMU Tdt-3140, specimens 1, 5) with same data as lectotype; one paralectotype larva (ZMMU Tdt-3142, specimen 1) ex Crocidura sp. No 247, 1 June 1956, other data same as for lectotype. 
Remarks. The genus Lorillatum includes 11 species distributed in Southeast and East Asia (VercammenGrandjean \& Langston 1976; Li et al. 1997; Stekolnikov 2021). Lorillatum attapinum differs from all other species

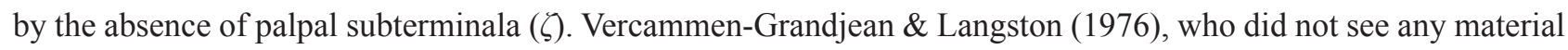
on this species, indicated the presence of the palpal subterminala in the diagnosis of $L$. attapinum obviously by a mistake. On the contrary, these authors did not notice the subterminala in L. mastigophorum (Nadchatram, 1963), as evident from their description and figures, although this seta is present according to the original description (Nadchatram 1963). Lorillatum attapinum differs from L. mastigophorum, in addition to the absence of palpal subterminala, by the presence of one mastifemorala and two mastitibialae, vs. one mastifemorala, one mastigenuala, one mastitibiala, and one mastitarsala. However, stability of these characters is not evident, since the level of ciliation of mastisetae can vary at least in L. attapinum. Thus, Schluger et al. (1963) reported on the presence of one mastifemorala, one mastigenuala, and one mastitibiala in this species, but did not mention mastitarsala. Measurements and numbers of idiosomal setae in these species are very similar.

Lorillatum attapinum also shares its $\mathrm{fPp}=\mathrm{B} / \mathrm{N} / \mathrm{NNB}(\mathrm{N})$ with $L$. kianjoei (Nadchatram and Traub, 1964) and $L$. panitae (Nadchatram and Traub, 1964), but differs from L. kianjoei in having the greater number of idiosomal setae (DS $=51-56$ and $\mathrm{fD}=2 \mathrm{H}-[8-2]-10-\ldots$ vs. $42-45$ and $2 \mathrm{H}-8-8-\ldots)$ ) and the presence of at most one mastigenuala vs. two, and from $L$. panitae in having shorter legs ( $\mathrm{Ip}=924-1056$ vs. 1248), lesser number of idiosomal setae (two humeral setae vs. four, $\mathrm{fD}=2 \mathrm{H}-[8-2]-10-\ldots$ vs. $4 \mathrm{H}-[10-2]-13-\ldots, \mathrm{NDV}=87-91 \mathrm{vs} .112$ ), and rounded anterolateral shoulders of scutum vs. sharply angulate.

\section{Genus Trombiculindus Radford, 1948}

\section{Trombiculindus griselda (Schluger, Grochovskaja, Ngu, Hoe and Tung, 1963)}

(Figs. 20-22)

Trombicula (Trombiculindus) griselda Schluger, Grochovskaja, Ngu, Hoe and Tung, 1963: 699, figs. 36-42.

Leptotrombidium (Trombiculindus) griseldae: Vercammen-Grandjean \& Langston 1976: 641, pl. 182.

Leptotrombidium (Trombiculindus) griselda: Chau et al. 2007: 63, fig. 29.

Trombiculindus griseldae: Kudryashova 2004: 20.

Trombiculindus griselda: Stekolnikov 2021: 145.

Diagnosis. $\mathrm{SIF}=7 \mathrm{~B}-\mathrm{B}-3-2111.0000 ; \mathrm{fsp}=7.7 .7 ; \mathrm{fCx}=1.1 .1 ; \mathrm{fSt}=2.2 ; \mathrm{fPp}=\mathrm{N} / \mathrm{N} / \mathrm{BNN} ; \mathrm{fSc}: \mathrm{AM} \geq \mathrm{PL}>\mathrm{AL} ; \mathrm{Ip}$ $=713-803 ; \mathrm{fD}=2 \mathrm{H}-8-6-6-2-4-2(4-2-2) ; \mathrm{DS}=24-30 ; \mathrm{V}=21-27 ; \mathrm{NDV}=45-56$. Standard measurements of type series given in Table 8 .

Description (larva) (based on lectotype and 13 paralectotypes, fD recorded in one specimen). IDIOSOMA (Figs. 20A, 21B-H). Eyes 2+2; 24-30 dorsal idiosomal setae, including one pair of humeral setae, arranged 2H8-6-6-2-4-2 (posterior 3 rows can be also recorded as 4-2-2); 4 sternal setae; 21-27 ventral setae; NDV = 45-56. Humeral and dorsal idiosomal setae broadly foliate, ovate, with pointed end, irregularly covered with thick scalelike setules; caudal and postanal setae less expanded, lanceolate, sparsely covered with small scalelike setules; preanal setae setiform, covered with long thin barbs.

GNATHOSOMA (Fig. 22A, B). Cheliceral blade with tricuspid cap; gnathobase covered with puncta and bears 1 pair of branched gnathocoxal (tritorostral) setae; cheliceral base and palpal femur covered with puncta; galeal (deutorostral) seta branched; palpal claw with 3 prongs; setae on palpal femur and genu nude, dorsal palpal tibial setae branched, lateral and ventral palpal tibial setae nude; palpal tarsus with 7 branched setae and tarsala $(\omega)$.

SCUTUM (Figs. 20, 21A). Nearly hexagonal, sparsely covered with small puncta, greatly projected posterior to PL, bases of AL and PL situated close to each other, posterior margin slightly concave in middle part; AM far posterior to level of AL, sensillary (trichobothrial) bases far posterior to level of PL (P-PL - PSB $=10-14 \mu \mathrm{m}$ ); AM and AL slightly expanded, covered with large barbs, PL broadly foliate, ovate, with pointed end, irregularly covered with thick scalelike setules; $\mathrm{AM} \geq \mathrm{PL}>\mathrm{AL}$; flagelliform sensilla (trichobothria) nude or having few branches in distal part. 
TABLE 8. Morphometric (AW-Ip, $\mu \mathrm{m}$ ) and meristic (DS-NDV) traits of Trombiculindus griselda (Schluger, Grochovskaja, Ngu, Hoe and Tung, 1963) $(\mathrm{n}=14)$.

\begin{tabular}{|c|c|c|c|}
\hline & Range & Mean & Lectotype \\
\hline AW & $69-78$ & 75 & 73 \\
\hline PW & $81-96$ & 91 & 90 \\
\hline SB & $41-52$ & 47 & 48 \\
\hline ASB & $21-34$ & 30 & 32 \\
\hline PSB & $15-18$ & 17 & 16 \\
\hline SD & $39-50$ & 47 & 48 \\
\hline P-PL & $27-30$ & 29 & 29 \\
\hline AP & $15-20$ & 17 & 17 \\
\hline AM & $51-56$ & 53 & 52 \\
\hline $\mathrm{AL}$ & $27-32$ & 29 & 32 \\
\hline PL & $47-54$ & 51 & 51 \\
\hline $\mathrm{H}$ & $48-58$ & 54 & 55 \\
\hline $\mathrm{D}_{\min }$ & $41-52$ & 47 & 47 \\
\hline $\mathrm{D}_{\max }$ & $53-64$ & 58 & 59 \\
\hline $\mathrm{V}_{\min }$ & $16-25$ & 20 & - \\
\hline $\mathrm{V}_{\max }$ & $39-49$ & 44 & - \\
\hline pa & 249-288 & 273 & 282 \\
\hline $\mathrm{pm}$ & $213-246$ & 228 & 213 \\
\hline $\mathrm{pp}$ & $248-284$ & 269 & 264 \\
\hline Ip & $713-803$ & 769 & 759 \\
\hline DS & $24-30$ & 28 & - \\
\hline V & $21-27$ & 25 & - \\
\hline NDV & $45-56$ & 53 & - \\
\hline
\end{tabular}

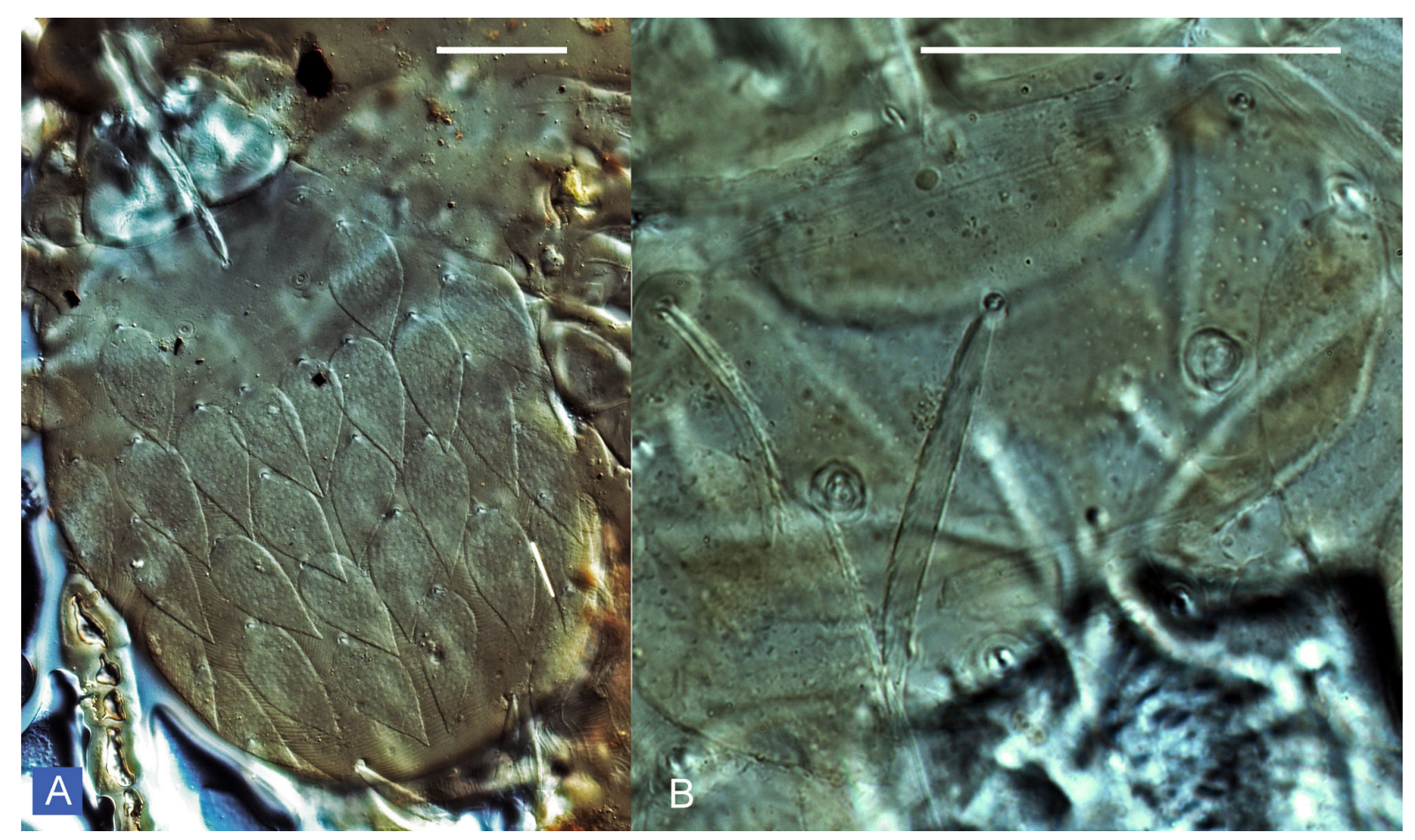

FIGURE 20. Trombiculindus griselda (Schluger, Grochovskaja, Ngu, Hoe and Tung, 1963). A, dorsal aspect of idiosoma in paralectotype ZMMU Tdt-3149, specimen 1 (AL and sensilla lost); B, scutum of lectotype (right sensillum and right AL lost). Scale bars: $50 \mu \mathrm{m}$. 
LEGS (Fig. 22C-E). All 7-segmented, with 1 pair of claws and claw-like empodium. Leg I: coxa with 1 branched seta (1B); trochanter 1B; basifemur 1B; telofemur 5B; genu 4B, 2 genualae $(\sigma)$, microgenuala $(\kappa)$; tibia 8B, 2 tibialae $(\varphi)$, microtibiala $(\kappa)$; tarsus $22 \mathrm{~B}$, tarsala $(\omega)$, microtarsala $(\varepsilon)$ proximal to tarsala, subterminala $(\zeta)$, parasubterminala (z), pretarsala ( $)$. Leg II: coxa 1B; trochanter 1B; basifemur 2B; telofemur 4B; genu 3B, genuala; tibia 6B, 2 tibialae $(\varphi)$; tarsus 16B, tarsala $(\omega)$, microtarsala $(\varepsilon)$ not observed, pretarsala $(\zeta)$. Leg III: coxa 1B; trochanter 1B; basifemur 2B; telofemur 3B; genu 3B, genuala; tibia 6B, tibiala; tarsus 15B.

Distribution and hosts. This species was described from North Vietnam, Quang Ninh Province, ex Rattus rattus (= R. rattus alexandrinus) and Leopoldamys edwardsi (Thomas) $[=R$. grochovskiae (nomen nudum)] (Schluger et al. 1963).

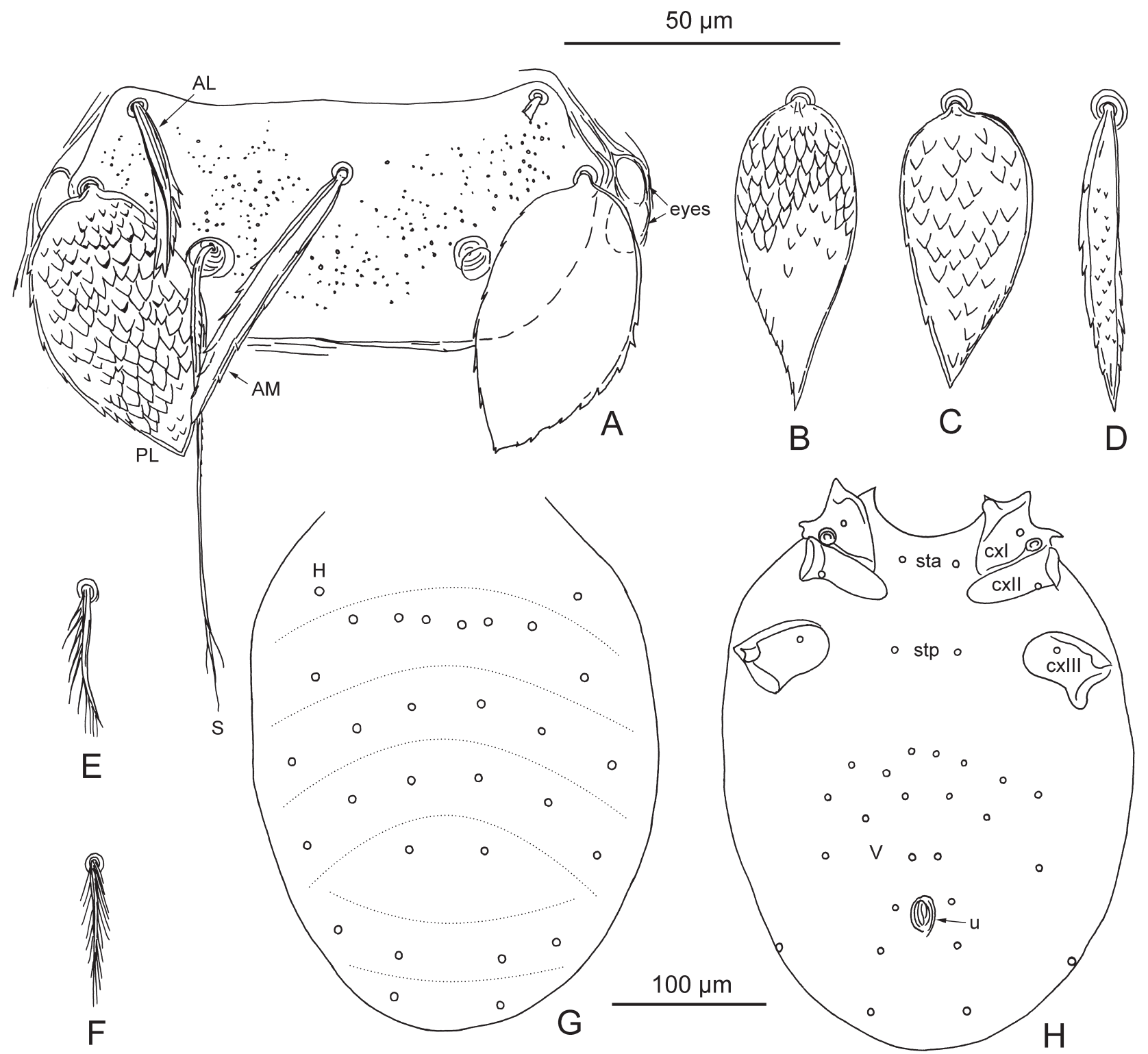

FIGURE 21. Trombiculindus griselda (Schluger, Grochovskaja, Ngu, Hoe and Tung, 1963). A, scutum of lectotype (right sensillum and right AL lost, setules of right PL not figured); B, humeral seta (C antero-marginal) of lectotype; $\mathbf{C}$, dorsal idiosomal seta of lectotype from anterior rows; D, caudal dorsal idiosomal seta of lectotype; $\mathbf{E}$, preanal seta of lectotype, lateral view; F, preanal seta of lectotype, ventral view; G, arrangement of dorsal idiosomal setae in paralectotype ZMMU Tdt-3148, specimen 4; H, ventral aspect of idiosoma in paralectotype ZMMU Tdt-3148, specimen 4. Abbreviations as in Fig. 2. Scale bars: $50 \mu \mathrm{m}$ (A-F), $100 \mu \mathrm{m}(\mathrm{G}, \mathrm{H})$. 

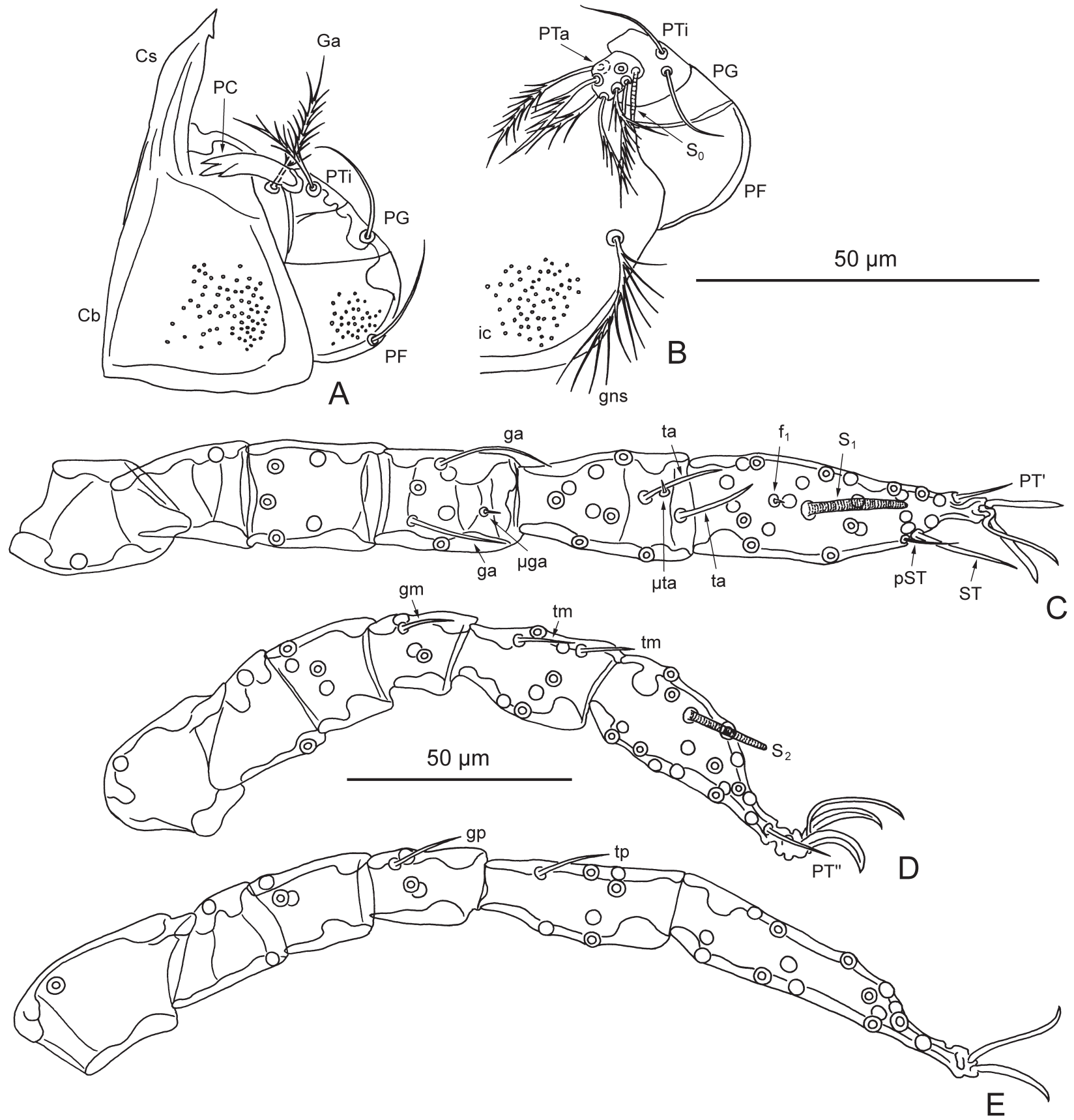

FIGURE 22. Trombiculindus griselda (Schluger, Grochovskaja, Ngu, Hoe and Tung, 1963). A, dorsal aspect of gnathosoma of lectotype; B, ventral aspect of gnathosoma of lectotype; C, leg I (trochanter-tarsus) of paralectotype ZMMU Tdt-3263, specimen 2; D, leg II (trochanter-tarsus) of paralectotype ZMMU Tdt-3263, specimen 2; E, leg III (trochanter-tarsus) of paralectotype ZMMU Tdt-3263, specimen 2 (one claw lost). Abbreviations as in Fig. 2. Scale bars: $50 \mu \mathrm{m}$ (A, B), $50 \mu \mathrm{m}(\mathrm{C}-\mathrm{E})$.

Type material examined. Lectotype larva (ZMMU Tdt-3151, specimen 1, designated here) ex L. edwardsi [labeled as R. grochovskii (nomen nudum)] No 44, VIETNAM: Quang Ninh Province, Ha Lam District, Ha Long (= Hon Gai), 6 February 1956, coll. I.M. Grochovskaja. Seven paralectotypes larvae (ZMMU Tdt-3147, specimen 1; ZMMU Tdt-3148, specimens 2, 3, 4; ZMMU Tdt-3263, specimens 1, 2, 3) ex L. edwardsi [labeled as $R$. grochovskii (nomen nudum)] No 35, 2 February 1956, other data same as for lectotype; five paralectotypes larvae (ZMMU Tdt3149, specimens 1, 2, 3, 4, 6) ex L. edwardsi [labeled as R. grochovskii (nomen nudum)] No 37, other data same as for lectotype; one paralectotype larva (ZMMU Tdt-3150, specimen 1) ex L. edwardsi [labeled as R. grochovskii (nomen nudum)] No 39, 3 February 1956, other data same as for lectotype.

Remarks. Trombiculindus includes 59 species distributed in Southeast, East, South, and Central Asia 
(Vercammen-Grandjean \& Langston 1976, Li et al. 1997, Stekolnikov 2021). Trombiculindus griselda shares the most part of characters with T. cuneatum Traub and Evans, 1951. The setation of palps and legs, number and arrangement of idiosomal setae, shape and measurements of scutum are almost identical in these species. Both species have slightly expanded AM and AL, but broadly foliate PL, H, and other dorsal idiosomal setae. Trombiculindus griselda differs from T. cuneatum in having foliate setae shorter and, therefore, relatively wider (PL 47-54, H 48-58, $\mathrm{D}_{\max }$ 53-64 vs. 60-70, 58-68, and 61-70, respectively) and irregularly covered with thick scalelike setules (vs. foliate setae with 8-9 longitudinal rows of setules); shorter AM (51-56 vs. 63-64) and AM > PL vs. PL > AM; and sensilla nude or with a few branches in distal half (vs. sensilla covered with small cilia in proximal part and up to 29-32 branches in distal two thirds).

\section{Discussion}

There are two revisions of the genus Leptotrombidium on the global scale that can be useful in taxonomic investigations at present. The book published by Vercammen-Grandejan \& Langston (1976) remains the most reliable source for the identification of Leptotrombidium species. Browsing the plates of figures in this work, with subsequent checking by the descriptions and tables of measurements, allows an easy and exact identification of the species known at that time. The work of Stekolnikov (2013), which includes only short diagnoses of species (except for six new) and a key, is difficult to use for identification as our experience has shown. Since the actual values of quantitative traits can deviate from those given in the descriptions, in many cases, using the key often fails. However, this monograph is useful as a checklist, which includes twice more species of Leptotrombidium s. str. than the previous revision of the genus. In addition, the subdivision of the genus into species groups, as the result of cluster analysis, can successfully serve to seek for possible synonyms, as evident from the results of the present work.

Noteworthy is the significant overlap of species contents of the magnum group according to Vercammen-Grandejan \& Langston (1976) and Stekolnikov (2013). This group includes L. magnum, L. globosum, L. keukenschrijveri, and L. dooleyi (synonymized here with L. magnum) in both concepts. In addition, in the latter paper this group includes only a series of species described in 1980s-90s. In the former concept, the magnum group also included L. kalrai (Radford, 1953), a species described from a single specimen and having an uniquely high number of idiosomal setae $(\mathrm{NDV}=260)$, and $L$. radfordi (Sinha, 1954), which differs from all other members of the group by the presence of branched ventral palpal tibial seta vs. nude ( $\mathrm{fPp}=\mathrm{N} / \mathrm{N} / \mathrm{BNB}$ vs. N/N/BNN). We can thus conclude that some aspects of the intuitive classification method applied by Vercammen-Grandjean coincide with the formal clustering algorithm used by Stekolnikov (2013).

Three of the eight species redescribed above are clearly distinct from other species of their genus and are not involved in taxonomic problems. Thus, $L$. arvinum is an easily identifiable species, which in addition to Vietnam, was recorded in Thailand, Laos, Malaysia, and China. It comprises a separate group, which probabaly should also include only one dubious species, $L$. saigoni, still known from a single specimen. Contrary to L. arvinum, the species L. gracipalpe, which is unique in its palpal formula, and L. horridum, which clearly differs from other species of its group, are currently known only from their type series.

Three other Leptotrombidium species from Vietnam redescribed herein were further recorded in Thailand by Lakshana (1973); however, verification of the latter records is desirable. Leptotrombidium globosum is easily recognizable from the previously described species of its group in having a specific shape of scutum, but some species described from China in 1980-90s could appear its synonyms. The second species, L. magnum, could potentially be conspecific with L. keukenschrijveri (India, Indonesia, Malaysia, and Thailand), from which it differs only by a larger scutum and longer legs. The third species, $L$. monstrosum, is probably conspecific with $L$. hanseni known from Thailand and Vietnam.

Lorillatum attapinum and Trombiculindus griselda are known only from their type series. The latter species can potentially be conspecific with T. cuneatum known from Burma, China, and India. Lorillatum attapinum is very similar to L. mastigophorum known from Laos, Malaysia, and Thailand, but we estimate the probability of its conspecificity with L. attapinum as low. Examination of the type series and new data on the intraspecific variation of T. cuneatum, L. mastigophorum, and other above-mentioned species are required to establish precisely the identity and differential characteristics for the pairs of similar species. 


\section{Acknowledgements}

We are grateful to S.V. Pichugina and O.V. Voltzit (Zoological Museum of Moscow State University, Moscow, Russia) for their help in our examination of the ZMMU chigger collection. We thank two anonymous reviewers for useful comments. The research was supported by the Russian Foundation for Basic Research (No 19-04-00532a to both authors) and by the Ministry of Science and Higher Education of the Russian Federation (AAAA-A16116021660101-5 to A.A. Antonovskaia; AAAA-A19-119020790133-6 to A.A. Stekolnikov).

\section{References}

Antonovskaia, A.A. \& Stekolnikov, A.A. (2021) Redescriptions of ten chigger mite species (Acariformes: Trombiculidae) from Vietnam. Zootaxa, 4969 (1), 1-53. https://doi.org/10.11646/zootaxa.4969.1.1

Chaisiri, K., Stekolnikov, A.A., Makepeace, B.L. \& Morand, S. (2016) A revised checklist of chigger mites (Acari: Trombiculidae) from Thailand, with the description of three new species. Journal of Medical Entomology, 53, 321-342. https://doi.org/10.1093/jme/tjv244

Chau, N.V., Hien, D.S. \& Van, N.T. (2007) Fauna of Vietnam. 16. Trombiculidae-Acarina, Siphonaptera. Science and Technics Publishing House, Ha Noi, 209 pp.

Goff, M.L., Loomis, R.B., Welbourn, W.C. \& Wrenn, W.J. (1982) A glossary of chigger terminology (Acari: Trombiculidae). Journal of Medical Entomology, 19, 221-238. https://doi.org/10.1093/jmedent/19.3.221

Kudryashova, N.I. (2004) Types of chigger mites (Trombiculidae) in the Zoological Museum of Moscow University. Zoologicheskie Issledovania, 7, 1-52.

Lakshana, P. (1973) A checklist of the trombiculid mites of Thailand (Prostigmata: Trombiculidae). US Army Medical Component, SEATO, Bangkok, 45 pp.

Li, J., Wang, D. \& Chen, X. (1997) Trombiculid mites of China: Studies on vector and pathogen of tsutsugamushi disease. Guangdong Science and Technology Press, Guangzhou, 570 pp. [in Chinese]

Nadchatram, M. (1963) Lorillatum, a new subgenus of Leptotrombidium, with description of a new species (Acarina: Trombiculidae). Pacific Insects, 5, 473-477.

Nadchatram, M. (1970) Nepal chiggers. 1. Species of the genus and subgenus Leptotrombidium, with synonymic notes (Prostigmata: Trombiculidae). Journal of Medical Entomology, 7, 145-163. https://doi.org/10.1093/jmedent/7.2.145

Santibáñez, P., Palomar, A., Portillo, A., Santibáñez, S. \& Oteo, J.A. (2015) The role of chiggers as human pathogens. In: Samie, A. (Ed.), An Overview of Tropical Diseases. Intech Open Limited, London, pp. 173-202. https://doi.org/10.5772/61978

Schindelin, J., Arganda-Carreras, I., Frise, E., Kaynig, V., Longair, M., Pietzsch, T., Preibisch, S., Rueden, C., Saalfeld, S., Schmid, B., Tinevez, J.Y., White, D.J., Hartenstein, V., Eliceiri, K., Tomancak, P. \& Cardona, F. (2012) Fiji: an open-source platform for biological-image analysis. Nature Methods, 9 (7), 676-682.

Schluger, E.G., Grochovskaja, I.M., Ngu, D.V., Hoe, N.X. \& Tung, D.K. (1959) New species of chiggers (Acariformes) from bats of North Viet-Nam. Zoologicheskiy Zhurnal, 38, 418-425. [in Russian]

Schluger, E.G., Grochovskaja, I.M., Ngu, D.V., Hoe, N.X. \& Tung, D.K. (1960a) Fauna of the chiggers (Acariformes, Trombiculidae) of North Viet-Nam. Parazitologicheskiy Sbornik Zoologicheskogo Instituta Akademii Nauk SSSR, 19, 169-193. [in Russian]

Schluger, E.G., Grochovskaja, I.M., Ngu, D.V., Hoe, N.X. \& Tung, D.K. (1960b) Species of the subgenus Leptotrombidium (Acariformes, Trombiculidae) from the Northern Viet Nam. Zoologicheskiy Zhurnal, 39, 1790-1801. [in Russian]

Schluger, E.G., Grochovskaja, I.M., Ngu, D.V., Hoe, N.X. \& Tung, D.K. (1960c) The trombiculid mites of the genus Gahrliepia (Acariformes, Trombiculidae) from North Viet-Nam. Entomologicheskoe Obozrenie, 39 (2), 462-476. [in Russian]

Schluger, E.G., Grochovskaja, I.M., Ngu, D.V., Hoe, N.X. \& Tung, D.K. (1961) The trombiculid mites (chigger mites) of the genera Doloisia Oudemans, 1910, and Traubacarus Audy et Nadchatram, 1957 (Acariformes, Trombiculidae) from North Viet-Nam. Entomologicheskoe Obozrenie, 40 (2), 448-453. [in Russian]

Schluger, E.G., Grochovskaja, I.M., Ngu, D.V., Hoe, N.X. \& Tung, D.K. (1963) Chigger-mites of the genus Trombicula (Acariformes, Trombiculidae) from Democratic Republic Viet Nam. Entomologicheskoe Obozrenie, 42 (3), 691-701. [in Russian]

Stekolnikov, A.A. (2013) Leptotrombidium (Acari: Trombiculidae) of the World. Zootaxa, 3728 (1), 1-173. https://doi.org/10.11646/zootaxa.3728.1.1

Stekolnikov, A.A. (2021) A checklist of chigger mites (Acariformes: Trombiculidae) of Southeast Asia. Zootaxa, 4913 (1), $1-163$. https://doi.org/10.11646/zootaxa.4913.1.1

Traub, R. \& Lakshana, P. (1966) Some chiggers of the subgenus Leptotrombidium from Thailand, with descritions of new 
species (Acarina, Trombiculidae). Journal of Medical Entomology, 3, 271-292. https://doi.org/10.1093/jmedent/3.3-4.271

Vercammen-Grandjean, P.H. \& Langston, R.L. (1976) The chigger mites of the World (Acarina: Trombiculidae et Leeuwenhoekiidae). III. Leptotrombidium complex. George Williams Hooper Foundation, University of California, San Francisco, $1061 \mathrm{pp}$.

Wang, D., Li, Z. \& Shi, L. (1988) Three new chiggers from Hubei Province, China (Acariformes: Trombiculidae). Acta Zootaxonomica Sinica, 13 (2), 137-143. [in Chinese]

Wen, T.H. (1984) Catalogue of the known species of sand mites and their hosts in China (Acariformes: Trombiculidae \& Leeuwenhoekiidae). In: Wen, T.H. (Ed.), Sand mites of China (Acariformes: Trombiculidae \& Leeuwenhoekiidae). Xue Lin Publishing House, Shanghai, pp. 295-339. [in Chinese]

Xiang, R.J. \& Wen, T.H. (1984) Note on Leptotrombidium (L.) miculum arvinum. In: Wen, T.H. (Ed.), Sand mites of China (Acariformes: Trombiculidae \& Leeuwenhoekiidae). Hue Lin Publishing House, Shanghai, p. 260. [in Chinese] 